UNIVERSIDADE DE BRASÍLIA

FACULDADE DE EDUCAÇÃO FÍSICA

PROGRAMA DE PÓS-GRADUAÇÃO STRICTO SENSU EM EDUCAÇÃO FÍSICA

EXERCÍCIO RESISTIDO COM RESISTÊNCIA ELÁSTICA E MÁQUINAS

PNEUMÁTICAS NO EQUILÍBRIO, FORÇA E MASSA MUSCULAR EM IDOSAS

DA COMUNIDADE: ENSAIO CLÍNICO ALEATORIZADO

MILENE SOARES NOGUEIRA DE LIMA

Brasília - DF

2016 
EXERCÍCIO RESISTIDO COM RESISTÊNCIA ELÁSTICA E MÁQUINAS PNEUMÁTICAS NO EQUILÍBRIO, FORÇA E MASSA MUSCULAR EM IDOSAS DA COMUNIDADE: ENSAIO CLÍNICO ALEATORIZADO

Dissertação apresentada ao Programa de PósGraduação em Educação Física da Universidade de Brasília, como requisito parcial à obtenção do título de Mestre em Educação Física.

Orientador: Prof. Dr. Wagner Rodrigues Martins

$$
\begin{gathered}
\text { Brasília-DF } \\
2016
\end{gathered}
$$




\section{MILENE SOARES NOGUEIRA DE LIMA}

Dissertação apresentada ao Programa de PósGraduação em Educação Física da Universidade de Brasília, como requisito parcial à obtenção do título de Mestre em Educação Física.

Banca examinadora:

Prof. Dr. Wagner Rodrigues Martins

(Orientador - FEF/UnB)

Prof. Dr. Rodrigo Carregaro

(Examinador Interno - FEF/UnB)

Prof $^{\mathrm{a}}$. Dr ${ }^{\mathrm{a}}$. Clarissa Cardoso dos Santos Couto da Paz

(Examinadora Externa - FCE/UnB)

Brasília - DF

2016 


\section{DEDICATÓRIA}

Dedico este trabalho à minha família,

pelo incentivo, amor e carinho. 


\section{AGRADECIMENTOS}

A Deus, fonte e princípio de toda sabedoria, que com seu olhar atento e cuidadoso me inspira e me acompanha, principalmente nos caminhos turbulentos.

Aos meus pais, Fernando Luís Fernandes e Maria do Socorro Soares Fernandes, através dos quais conheci o amor, e ao meu irmão Fernando Júnior, motivador e companheiro. Com vocês eu enfrentei os pequenos desafios diários desses anos de estudo. Os obstáculos somente tornaram-se pequenos pela compreensão e pela ajuda de vocês, agradeço por estarem sempre presentes. Amo vocês!

Ao meu namorado, Wesley Freitas, amigo e cúmplice, agradeço o seu carinho, sua motivação e por estar presente em todos os instantes. Por me escutar (mesmo que não entendesse o que eu falava) e por trazer a leveza nos meus momentos de angústia.

Ao meu orientador, Dr. Wagner Martins, que me ofereceu essa experiência de aprendizado e muito amadurecimento; à professora Dra. Marisete Safons, por todo o apoio e incentivo; ao professor Dr. Rodrigo Carregaro, membro da banca desde a fase de qualificação; à professora Dra. Patrícia Azeredo, pelo auxílio no recrutamento de idosos e no empréstimo de equipamentos. E, em especial, à professora Dra. Clarissa Cardoso, minha referência de profissionalismo, conhecimento e generosidade. A todos os professores com os quais já tive o prazer de aprender. A docência é uma atividade nobre por excelência, que inspira em nossas jovens mentes o desejo de conhecer, pesquisar e contribuir com o homem e seu universo.

Aos meus amigos, que às vezes me acompanhavam de perto e às vezes sentiam a minha ausência, agradeço pelas inúmeras vezes que me enxergam melhor do que eu sou. Vocês são as minhas fontes constantes de alegria e aprendizado.

Aos meus companheiros de pesquisa, Karina Lagoa e Gerson Júnior, esse trabalho é fruto dos nossos esforços e sacrifícios, agradeço por contribuírem tanto com o meu crescimento profissional quanto pessoal. Cada etapa foi vivenciada de maneira única; a busca pelos voluntários, as reuniões até tarde da noite, a preparação dos lanches, a dificuldade das coletas e as idas e vindas do transporte. Enfim, construímos um trabalho no qual os resultados vão além do que é mensurável.

Ao Rafael Máximo, que auxiliou com a estatística, pelo seu profissionalismo e por sua paciência e a Karina Mattos revisora de português, por sua simpatia e cooperação.

Aos alunos de iniciação científica, Tito, Anderson, More, Wanessa, Carlos, Adriele, Andressa e Gustavo, gostaria de agradecer por acreditarem no projeto, pelo carinho com os 
voluntários, pela boa vontade e animação de vocês. Aos alunos que estiveram no projeto, espero que tenha sido proveitoso.

Aos protagonistas desse projeto, meus queridos voluntários, graças aos senhores, a realização foi possível, construímos laços de amizade, afeto e respeito. Ao longo desse tempo de convivência, aprendi o que é ser sábia antes de envelhecer e o que realmente importa nessa vida.

Aos professores responsáveis pelos laboratórios, aos funcionários da Faculdade de Educação Física e da Faculdade da Ceilândia, por estarem sempre dispostos a ajudar, seria tudo mais difícil sem vocês.

Às agências financiadoras CAPES e CNPq.

Enfim, a todos que colaboraram para o êxito dessa empreitada, ofereço o meu sincero: obrigada! 


\section{RESUMO}

O uso das máquinas de musculação e da resistência elástica é considerado eficaz e seguro para aumentar a força muscular, massa e equilíbrio. No entanto, ainda são escassos os trabalhos que investigaram, se os efeitos da resistência elástica são semelhantes com os obtidos nos exercícios com máquinas, além disso, e se os efeitos permanecem após 10 semanas de destreinamento. A proposta desse estudo foi comparar 12 semanas de exercícios resistidos (duas vezes por semana, exercícios de tronco, membros superiores e inferiores) e 10 semanas de destreinamento com máquinas pneumáticas versus resistência elástica na força muscular, massa e equilíbrio em mulheres idosas da comunidade: ensaio clínico aleatorizado. Cinquenta e sete (57) mulheres idosas foram aleatorizadas em dois grupos, GMP (grupo máquinas pneumáticas) e GRE (grupo resistência elástica). Vinte participantes (20) finalizaram o estudo em cada grupo. No GMP, com médias de idade de 67,5 \pm 5,18 anos, altura de 1,53 $\pm 0,065 \mathrm{~m}$, massa corporal de 67,96 $\pm 11,24 \mathrm{Kg}$ e índice de massa corporal de 29,03 $\pm 4,42 \mathrm{Kg} / \mathrm{m} 2$. No GRE, com médias de idade de 66,1 $\pm 4,72$ anos, altura de 1,55 $\pm 0,073 \mathrm{~m}$, massa corporal de $69,62 \pm 10,14 \mathrm{Kg}$ e índice de massa corporal de $28,89 \pm 3,48 \mathrm{Kg} / \mathrm{m} 2$. As variáveis foram mensuradas nos momentos pré avaliação, pós treinamento e destreinamento; o pico de torque para extensores de joelho (PTJ) e flexores de cotovelo (PTC) nas velocidades de $60 \% \mathrm{~s}$ e $180 \%$ s, teste timed up and go (TUG) e teste de alcance funcional (TAF). Foi encontrada uma redução no tempo de execução do teste TUG em ambos os grupos $(\mathrm{p}=0,000)$ e não houve perdas durante o destreinamento $(\mathrm{p}>0,05)$. No TAF, apenas o GMP apresentou mudanças durante o PÓS $(p=0,011)$ e não ocorreram perdas no destreinamento $(p>0,05)$. No que se refere à massa livre de gordura nos membros inferiores, no GRE ocorreram mudanças estatísticas $(\mathrm{p}=0,001)$. Referente à força muscular, os membros inferiores em ambas as velocidades e em ambos os grupos obtiveram ganhos $(\mathrm{p}=0,000)$, entretanto, após as 10 semanas de destreinamento apresentaram perdas ( $\mathrm{p}<0,05)$. O GMP apresentou ganhos nos membros superiores em ambas as velocidades $(p<0,05)$ e perdas estatísticas durante o destreinamento $(\mathrm{p}<0,05)$. O GRE apresentou diferenças estatísticas na velocidade de $60 \%$ $(\mathrm{p}=0,012)$ e houve mudanças durante $\mathrm{o}$ destreinamento $(\mathrm{p}=0,000)$. Os dois tipos de treinamento não apresentaram diferenças estatísticas, nas fases analisadas.

Palavras-chave: Envelhecimento, força muscular, massa muscular, equilíbrio, treinamento de resistência. 


\begin{abstract}
The use of weight machines and elastic resistance is considered safe and effective to increase muscle strength, mass and balance. However, there are still few studies that investigated the effects of elastic resistance are similar to those obtained with the exercise machine, in addition, the effects remain after 10 weeks of detraining. The purpose of this study was to compare 12 weeks of resistance training (twice a week, trunk exercises, upper and lower limbs) and 10 weeks of detraining with pneumatic machines versus elastic resistance in muscle strength, mass and balance in community elderly women: randomized clinical trial. Fifty-seven (57) elderly women were randomized into two groups, GMP (group pneumatic machines) and GER (group elastic resistance). Twenty participants (20) completed the study in each group. In the GMP, with an average age of $67.5 \pm 5.18$ years, height $1.53 \pm 0.065 \mathrm{~m}$, body mass $67.96 \pm 11.24 \mathrm{~kg}$ and body mass index $29.03 \pm 4.42 \mathrm{~kg} / \mathrm{m}^{2}$. In GRE, with mean age of $66.1 \pm 4.72$ years, height $1.55 \pm 0.073 \mathrm{~m}$, body mass $69.62 \pm 10.14 \mathrm{~kg}$ and body mass index $28.89 \pm 3.48 \mathrm{~kg} / \mathrm{m}^{2}$. The variables were measured in pre-evaluation, post training and detraining; peak torque of knee extensors (PTJ) and elbow flexors (PTC) at speeds of $60 \%$ and $180 \%$, timed up and go test (TUG) and functional reach test (FRT). It was found a reduction in the TUG test execution time in both groups $(\mathrm{p}=0.000)$ and no losses during detraining ( $p>0.05)$. In FRT, only the GMP changed during the POST $(p=0.011)$ and no losses in detraining ( $p>0.05)$. As regards the fat free mass in the lower limbs, in the GER changes occurred statistics $(\mathrm{p}=0.001)$. Regarding the muscle strength, the legs at both speeds and in both groups had gains $(\mathrm{p}=0.000)$, however, after 10 weeks of detraining showed loss ( $p<0.05)$. GMP showed gains in the upper limbs at both speeds $(\mathrm{p}<0.05)$ and loss statistics for detraining ( $p<0.05)$. The GER showed statistical differences in speed of $60 \% \mathrm{~s}(\mathrm{p}=0.012)$ and there were changes during detraining $(\mathrm{p}=0.000)$. Both types of training did not show differences in the analyzed stage.
\end{abstract}

Keywords: Aging, muscle strength, muscle mass, balance, resistance training. 


\section{LISTA DE FIGURAS}

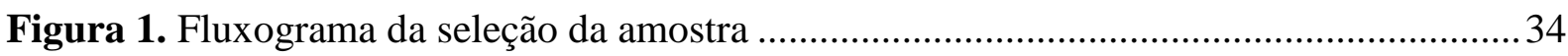

Figura 2. Exercício supino realizado no GRE e GMP fase inicial e final ............................. 70

Figura 3. Exercício remada realizado no GRE e GMP fase inicial e final ............................ 71

Figura 4. Exercício puxada alta realizado no GRE e GMP fase inicial e final ........................72

Figura 5. Exercício tríceps realizado no GRE e GMP fase inicial e final ..............................73

Figura 6. Exercício abdução realizado no GMP e GRE fase inicial e final ........................... 74

Figura 7. Exercício de extensão de quadril realizada no GMP e GRE fase inicial e final. ..... 75

Figura 8. Exercício deslocamento no GRE e Abdução no GMP .......................................... 76

Figura 9. Exercício de flexão joelho realizado no GRE e GMP. ......................................... 77

Figura 10. Exercício de extensão de joelho no GRE e GMP ................................................... 78 


\section{LISTA DE TABELAS}

Tabela 1. Treinamento resistido realizado nos GRE e GMP, membros superiores e

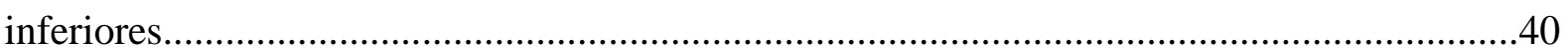

Tabela 2. Descrição do período de treinamento realizado durante as fases de teste de RM, familiarização e treinamento 41

Tabela 3. Características antropométricas dos participantes dos GMP e GRE ...................... 44

Tabela 4. Resultados das medidas de desfecho, médias, desvio padrão e tamanho do efeito. 45 


\section{LISTA DE ABREVIATURAS}

ACSM = American College of Sports and Medicine

AVD's = Atividades de vida diária

$\mathrm{CP}=$ Controle postural

DEXA = Absormetria de Raio-x de Dupla Energia

$\mathrm{ER}=$ Exercício Resistido

FCE $=$ Faculdade de Ceilândia

FEF $=$ Faculdade de Educação Física

GMP = Grupo de Treinamento Máquina

GRE $=$ Grupo de Treinamento Resistência Elástica

IBGE = Instituto Brasileiro de Geografia e Estatística

IMC = Índice de Massa Corporal

MLG = Massa Livre de Gordura

MLGI = Massa Livre de Gordura Membros Inferiores

MLGS = Massa Livre de Gordura Membros Superiores

MLGT $=$ Massa Livre de Gordura Membros Total

OMS = Organização Mundial da Saúde

PTC $=$ Pico de Torque da flexão do Cotovelo

PTJ = Pico de Torque da extensão de Joelho

$\mathrm{RM}=$ Repetições Máximas

TAF $=$ Teste de Alcance Funcional

TCLE $=$ Termo de Consentimento Livre e Esclarecido

$\mathrm{TR}=$ Treinamento Resistido

TUG $=$ Timed Up and Go

UnB = Universidade de Brasília 


\section{SUMÁRIO}

1. INTRODUÇÃ

2. OBJETIVO GERAL ............................................................................................................... 19

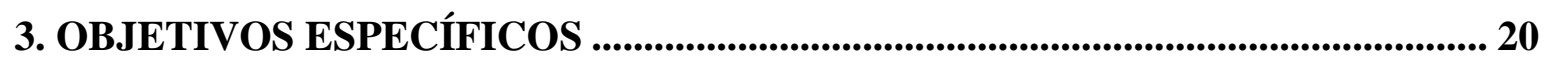

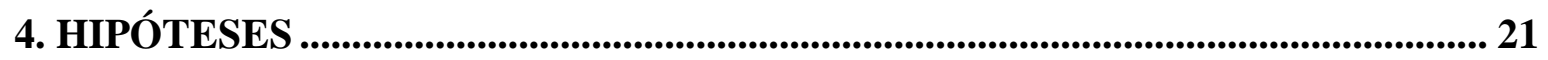

5. REVISÃO DA LITERATURA ................................................................................. 22

5.1 EPIDEMIOLOGIA DO ENVELHECIMENTO: UMA VISÃO DO BRASIL E DO

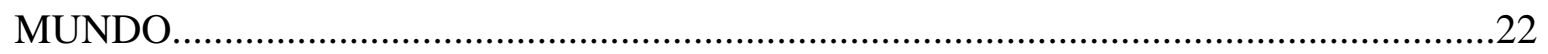

5.2 O ENVELHECIMENTO E SUA INFLUÊNCIA NOS MECANISMOS FISIOLÓGICOS E

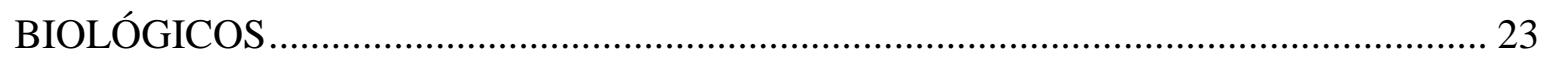

5.3 CAPACIDADE FUNCIONAL DURANTE O ENVELHECIMENTO ........................ 24

5.4 A REDUÇÃO DA FORÇA MUSCULAR E OS EFEITOS PROVOCADOS PELO

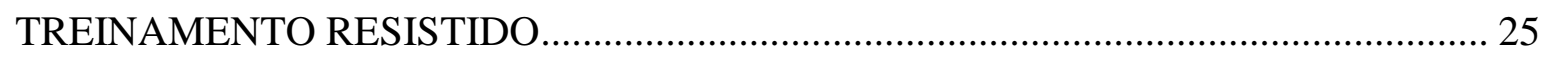

5.5 A PERDA DA MASSA MUSCULAR E AS SUAS CONSEQUÊNCIAS DURANTE O

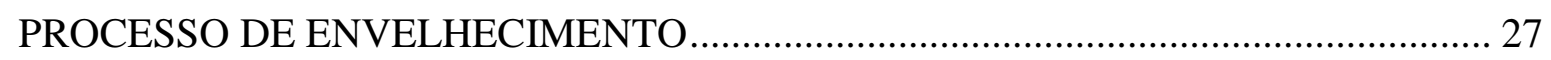

5.6. EQUILÍBRIO E MOBILIDADE DURANTE O ENVELHECIMENTO...................... 28

5.7 TREINAMENTO RESISTIDO REALIZADO COM MÁQUINAS PNEUMÁTICAS E

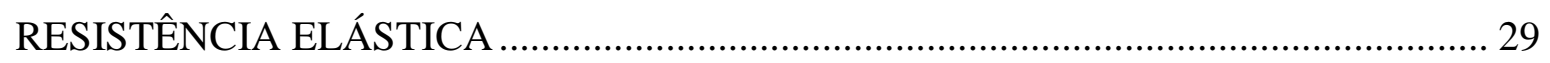

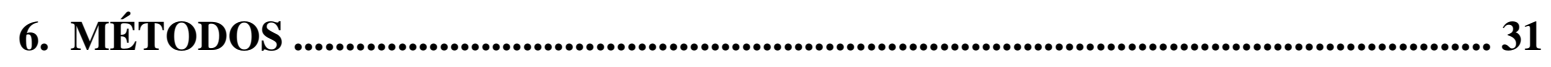

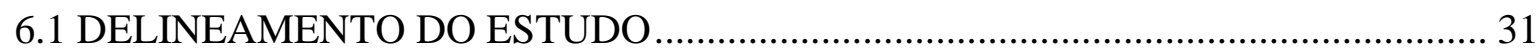

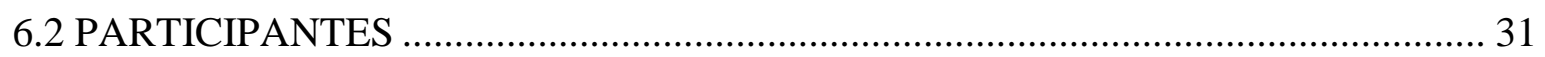

6.2.1 Critérios de inclusão............................................................................................32

6.2.2 Critérios de exclusão ...................................................................................................32

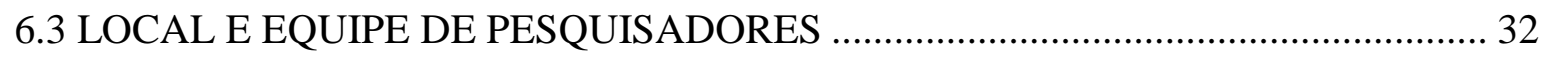

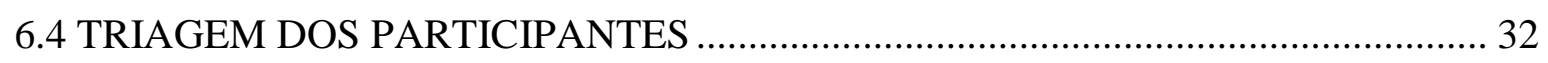

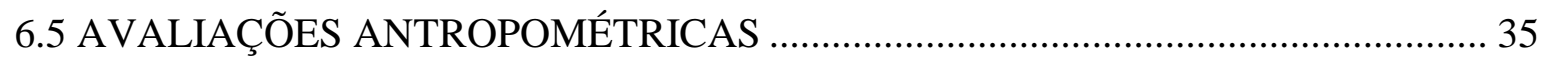

6.6 MEDIDAS DE DESFECHOS ......................................................................... 35

6.6.1 Avaliação dos testes de mobilidade e equilíbrio .........................................................35

6.6.2 Avaliação da força muscular ...........................................................................................37

6.6.3 Avaliação da massa muscular .......................................................................................38 


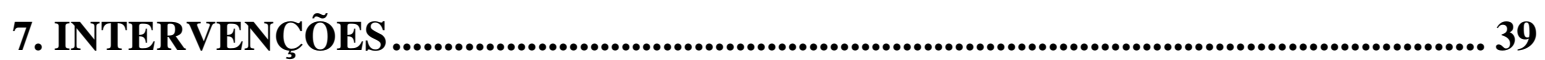

7.1 VARIÁVEIS DE MANIPULAÇÃO DO TREINAMENTO ………………………...... 39

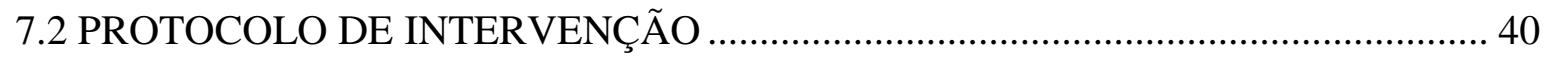

7. 3 EQUIPAMENTOS UTILIZADOS E A PROGRESSÃO DE CARGAS …………...... 41

7.3.1 Resistência elástica e máquinas pneumáticas ...............................................................41

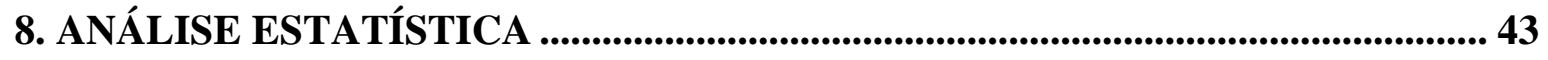

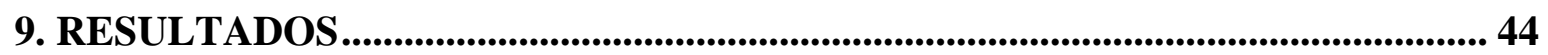

9.1 CARACTERÍSTICAS DOS PARTICIPANTES ……………………………........... 44

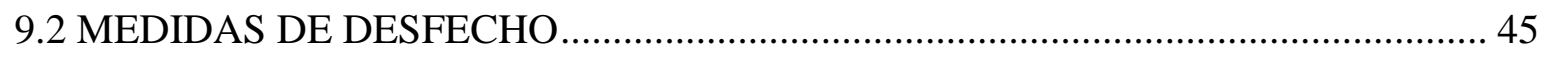

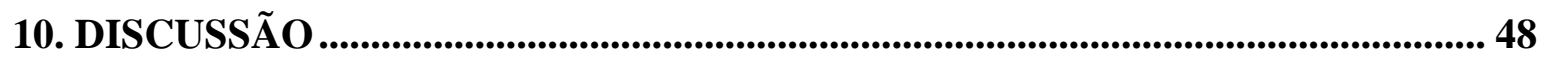

10.1 TESTES DE MOBILIDADE E EQUILÍBRIO...................................................... 48

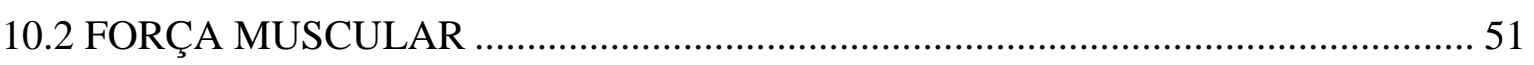

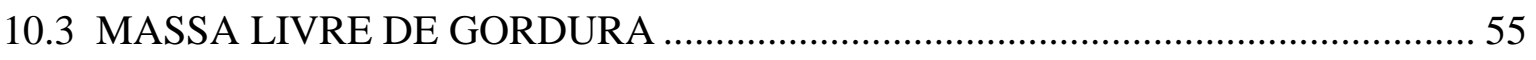

11. LIMITAÇÕES DO ESTUDO ................................................................................... 57

CONSIDERAÇÕES FINAIS ................................................................................... 58

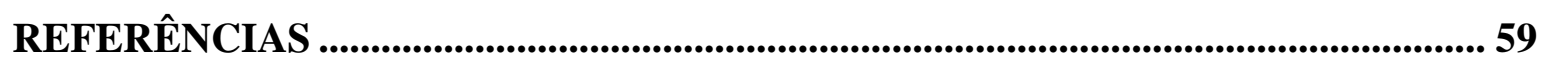

APÊNDICE A - TERMO DE CONSENTIMENTO LIVRE E ESCLARECIDO ...... 66 APÊNDICE B - QUESTIONÁRIO PARA IDENTIFICAÇÃO INICIAL DOS CRITÉRIOS DE SELEÇÃO DA AMOSTRA................................................................................. 68

ANEXO A- PARECER DO COMITÊ DE ÉTICA .......................................................... 69

ANEXO B - IMAGENS DOS EXERCÍCIOS REALIZADOS NAS MÁQUINAS PNEUMÁTICAS E NA RESISTÊNCIA ELÁSTICA.................................................... 70 



\section{INTRODUÇÃO}

O envelhecimento é conceituado como o processo dinâmico e progressivo, no qual há modificações morfológicas, funcionais, bioquímicas e psicológicas, que são determinadas pela redução da capacidade de adaptação homeostática perante a sobrecarga funcional do organismo, ocasionando, maior vulnerabilidade e maior incidência de doenças. O início da velhice é indefinido por depender de fatores individuais, culturais, genéticos e sociais, entretanto, socialmente e cronologicamente, essa fase inicia-se aos 60 anos de idade e pode atingir 100 anos ou mais (FREITAS, 2011).

Apesar dessa definição é importante salientar que na velhice ocorrem as mudanças típicas que são determinadas pela espécie e não são patológicas, e mesmo na presença de doenças e agravantes, o idoso pode viver bem a sua velhice, com as condições que têm, desde que seja capaz de encontrar recursos pessoais, estratégias de reabilitação e de promoção da saúde (NERI; YASSUDA; CACHIONI, 2004). Além disso, as principais condições associadas a velhice bem sucedida são: ausência de doenças físicas e mentais crônicas e de incapacidades funcionais que comprometem o seu desempenho (NETTO, 2007).

De acordo com os dados do Instituto Brasileiro de Geografia e Estatística (IBGE), a estimativa é de que até o ano de 2060, o número de idosos chegue a 73 milhões (IBGE, 2010). Em países como o Brasil, onde impera a desigualdade social e existem poucas políticas de atendimento das necessidades evolutivas, o envelhecer acarreta ônus econômico e carências nas áreas de saúde (GRAGNOLATI et al., 2012; WONG, LAURA RODRÍGUEZ; MOREIRA, 2000), sendo assim a tendência ao estudo do envelhecimento soma-se a necessidade de estabelecer as relações e os padrões de envelhecimento disfuncional assumido como uma das possibilidades desse processo, contudo, contribuir para evitar ou adiar essas alterações e produzir estratégias que permitam a reabilitação de desempenhos prejudicados.

A manutenção da funcionalidade, é considerada um forte indicador da saúde e está relacionada com a interação de várias funções, entre elas a capacidade física e psicognitiva, que sustentam a realização das atividades de vida diária e a participação social e comunitária do idoso (LOPES; SANTOS, 2015). As mudanças que caracterizam a senescência, associadas a fatores ambientais e pessoais, predispõem o idoso a maior vulnerabilidade e incidência de comorbidades, que comprometem a independência funcional e o nível de Atividade $e$ Participação (ORGANIZAÇÃO MUNDIAL DA SAÚDE, 2004).

Diante desse contexto, os atributos físico-funcionais e percepto-cognitivos que são comumente associados à capacidade funcional são: composição corporal, desempenho 
muscular, desempenho em testes de mobilidade, equilíbrio, acuidade visual, cognição associada à tarefa e cognição relacionada à função cognitiva e à atenção dividida (PERRACINI; FLÓ, 2011).

No que diz respeito às alterações de composição corporal presentes no envelhecimento, a sarcopenia refere-se à perda relacionada à massa muscular e as suas manifestações clínicas associadas com a idade (BRIAN CLARK; TODD MANINI, 2011). Além da perda de massa muscular, as fibras musculares também são parcialmente infiltradas por tecido adiposo e tecido conectivo, principalmente com acúmulos na cavidade abdominal, levando à diminuição da massa livre de gordura (MLG) (LANDI et al., 2013). Há um declínio tanto no número de células musculares quanto no conteúdo protéico das células remanescentes, com uma redução associada e rápida da massa das células. Essas mudanças se traduzem em alterações na força muscular com prejuízo para o desempenho físico, aumento do risco de quedas, e, muitas vezes, pode levar à fragilidade (LANG et al., 2010). O declínio de força muscular associado a perda de massa muscular pode comprometer o CP (controle postural) tanto em situações de manutenção, quanto em importantes respostas dinâmicas, como movimentos em perturbações externas (PERRACINI; FLÓ, 2011).

A força muscular humana é definida pelo torque ou força produzida por um músculo durante uma contração voluntária máxima, sendo o seu pico máximo por volta dos 25 a 30 anos (SPIRDUSO, 2005). A partir daí, há um declínio constante e universal. O trabalho muscular é necessário para a manutenção de quase todas as funções do corpo, como postura, locomoção, respiração e digestão além disso, a perda da mobilidade é associada a perda da força muscular, interferindo na capacidade de realizar transferências, subir e descer escadas e durante a marcha (FREITAS, 2011). A preservação da força muscular é uma função primordial para o equilíbrio, tanto em contrações concêntricas como excêntricas seja em cadeias abertas ou fechadas (HORAK, F. B., 2006) .

O equilíbrio é considerado como uma tarefa motora complexa que envolve a interação de múltiplos processos sensório-motores, o planejamento e a execução de padrões de movimento flexíveis para que os objetivos do CP sejam alcançados. Entendendo a capacidade do indivíduo de se ajustar ao contexto ambiental, as demandas específicas da tarefa e a intencionalidade do indivíduo. O desempenho de cada idoso em relação ao CP depende das estratégias utilizadas por cada indivíduo para manter a estabilidade e orientação em uma dada tarefa, levando-se em conta suas limitações específicas (HORAK, B. F., 1997; HORAK, F. B., 2006; SHUMWAY-COOK, ANNE WOOLLACOTT, 2010). 
Durante as últimas duas a três décadas, os estudos demonstraram os efeitos das modalidades de exercício na força, massa muscular e equilíbrio, entre eles o exercício resistido (ER) (GERAGE et al., 2013; MATSUDO; MATSUDO; NETO, 2000; RICE; KEOGH, 2008). Apesar dos exercícios com resistência melhorarem a força voluntária máxima, nos idosos, os resultados funcionais são limitados porque os benefícios de força nem sempre são transferidos efetivamente para melhorias em equilíbrio, tarefas funcionais, ou atividades da vida diária (RICE; KEOGH, 2009).

Estudos abrangendo Tai Chi Chuan, caminhadas, exercícios resistidos com máquinas e pesos livres, resistência elástica, treinos combinados e treinos funcionais demonstraram gerar benefícios em mais de um aspecto da aptidão física e ainda no desempenho funcional de idosos entretanto, práticas de metodologia replicável, baixo custo e com alto nível de adesão são alvo de pesquisas quando se trata da aplicação destas práticas para a população em geral (DE VREEDE et al., 2004; HANSON et al., 2009; HOWE et al., 2007; KREBS; SCARBOROUGH; MCGIBBON, 2007).

De acordo com o último posicionamento do American College of Sports and Medicine (ACSM) sobre a progressão dos exercícios resistidos para a população de idosos, recomendase, para iniciantes, um programa realizado com máquinas e pesos livres (CHODZKO-ZAJKO et al., 2009). Recentemente, as máquinas pneumáticas têm sido utilizadas como um recurso para o treinamento resistido, já que através do seu estímulo mecânico, a massa corporal é a única inércia que deve ser vencida para iniciar o movimento e reduzindo o risco de lesões (FROST; JOHN; NEWTON, 2010; PELTONEN; HAKKINEN; AVELA, 2013). Porém, na maioria das vezes, os usos desses equipamentos de musculação não são acessíveis à população idosa, quer seja pelo custo envolvido na adesão das academias de musculação, quer seja pela dificuldade em encontrar espaços especializados no treinamento de idosos (COLADO, J. C. et al., 2010; MARTINS et al., 2015; MOTALEBI; LOKE, 2014) .

A prática de exercícios com dispositivos elásticos podem ser uma alternativa às práticas convencionais em academias. $\mathrm{O}$ interesse pelos dispositivos elásticos pode ser comprovado pelo crescimento exponencial do número de publicações científicas. Ensaios clínicos demonstraram a viabilidade e a praticidade de se trabalhar com elásticos, demonstrando também sua eficácia para ganhos de força muscular e dinâmica (MARTINS et $a l .$, 2014). O uso da resistência elástica permite a possibilidade de trabalhar com padrões de movimentos mais funcionais quando comparados às máquinas de musculação tradicionais, sendo uma estratégia a ser considerada para reduzir os efeitos fisiológicos que acompanham o envelhecimento (COLADO, J. C. et al., 2010; HOSTLER et al., 2001; WILSON et al., 2014). 
Os estudos que realizaram intervenções com resistência elástica em idosos demonstraram resultados positivos principalmente nos incrementos de desempenho muscular, como dito anteriormente, no entanto, o presente estudo teve como proposta uma avaliação mais completa através de testes de mobilidade e equilíbrio, força muscular e massa livre de gordura, em idosas da comunidade.

Além disso, foi realizada a análise em relação aos ganhos provocados por ambas as modalidades durante um período de 10 semanas sem exercícios, para verificar a retenção dos efeitos da intervenção (destreinamento). Essa análise desempenha um papel importante no prolongamento e na antecipação dos efeitos durante o período de inatividade e na recuperação fisiológica ao retornar aos programas de treinamento, já que os ganhos durante essa fase podem ser reduzidos ou retornarem aos valores de pré-treino, quando o mesmo é interrompido (HENWOOD; TAAFFE, 2008).

A maioria dos estudos que investigaram os efeitos dos exercícios com resistência elástica em idosos que realizaram intervenções, de média e longa duração, com resultados, demonstrando modificações positivas na força muscular (COLADO, C. J.; N., 2008; HOSTLER et al., 2001) . Em relação aos programas de treinamento de curta duração (2-10 semanas) (MARIANO et al., 2013), existem poucos estudos que avaliaram o impacto da resistência elástica sobre a força muscular dos membros superiores e inferiores de idosos destreinados. Em relação à composição corporal, não existem evidências sobre o efeito desse tipo de exercício na massa muscular de idosos, seja em curto, médio ou longo prazo. Por outro lado, já existem evidências dos efeitos do treinamento de curta duração com pesos para o aumento da força, ativação e massa muscular em indivíduos idosos (FATOUROS G. IOANNIS et al., 2006; KREBS; SCARBOROUGH; MCGIBBON, 2007; ZECH et al., 2012).

Dessa maneira, entende-se a necessidade de preencher parte das lacunas de outras investigações, comparando as máquinas pneumáticas e a resistência elástica através de um programa de exercícios de 12 semanas, seguido de um período de destreinamento de 10 semanas, avaliando o desempenho nos testes de mobilidade e equilíbrio, força e massa livre de gordura, contribuindo para a identificação de novas estratégias para promover o bem-estar dessa população. 


\section{OBJETIVO GERAL}

Avaliar os efeitos de duas modalidades de exercícios resistidos com máquinas pneumáticas e resistência elástica na mobilidade e equilíbrio, força muscular e massa livre de gordura, em idosas da comunidade. 


\section{OBJETIVOS ESPECÍFICOS}

- Comparar os testes de mobilidade e equilíbrio, nos grupos máquinas pneumáticas e resistência elástica nas fases de avaliação inicial, pós-treinamento (12 semanas) e destreinamento (10 semanas) em idosas da comunidade;

- Comparar a força muscular, nos grupos máquinas pneumáticas e resistência elástica nas fases de avaliação inicial, pós-treinamento (12 semanas) e destreinamento (10 semanas) em idosas da comunidade;

- Comparar a composição da massa livre de gordura, nos grupos máquinas pneumáticas e resistência elástica nas fases de avaliação inicial, pós-treinamento (12 semanas) e destreinamento (10 semanas) em idosas da comunidade. 


\section{HIPÓTESES}

H0: Não haverá diferenças entre os grupos máquina e resistência elástica, em relação à mobilidade e equilíbrio, força muscular e massa livre de gordura;

H1: Haverá diferenças entre os grupos máquina e resistência elástica, em relação à mobilidade e equilíbrio, força muscular e massa livre de gordura. 


\section{REVISÃO DA LITERATURA}

\subsection{EPIDEMIOLOGIA DO ENVELHECIMENTO: UMA VISÃO DO BRASIL E DO MUNDO}

De acordo com a Organização Mundial da Saúde (2012), atualmente, a maior parte da população pode esperar viver até os 60 anos de idade ou mais. O envelhecimento ocorre de maneira rápida em todo o mundo, aliado aos fatores: redução das taxas de fertilidade, diminuição da natalidade e aumento da expectativa de vida (ORGANIZAÇÃO MUNDIAL DA SAÚDE -OMS, 2012).

Nos países desenvolvidos, o envelhecimento ocorreu de maneira lenta, sendo assim, os países elaboraram estratégias que envolvem políticas públicas, econômicas e de saúde, que conseguiram acompanhar esse crescimento no mesmo ritmo e velocidade, ou seja, o envelhecimento veio acompanhado do desenvolvimento econômico e da qualidade de vida. Infelizmente, na América Latina e no Brasil, o envelhecimento aconteceu de maneira acelerada e progressiva, sendo assim, não foi elaborado um planejamento para suprir as necessidades dessa população (WONG, LAURA RODRÍGUEZ; MOREIRA, 2000).

No Brasil, os dados do Instituto Brasileiro de Geografia e Estatística (IBGE, 2010), demonstraram que a população de idosos representa mais de 24 milhões de indivíduos e a estimativa é de que até o ano de 2060 esse número chegue a 73 milhões. O mesmo Instituto evidencia que a expectativa de vida no ano de 1960 era de 41 anos e em 2010 esse número passou para 75 anos, sendo assim, a expectativa quase dobrou em menos de 50 anos.

Restringindo esses dados para o Distrito Federal, existe a proporção de 7,6\% da população composta por idosos, totalizando 197.613 idosos. Assim como o número de mulheres ao estudar um contingente de idosos será superior, fenômeno chamado de “feminização da velhice" (GRAGNOLATI et al., 2012). A menor mortalidade da população feminina, os cuidados com a saúde e a melhor adaptação ao processo de envelhecimento, explica essa diferenciação na composição por sexo e faz com que cresça suas taxas de expectativa de vida (FREITAS, 2011).

A associação entre o envelhecimento e o aparecimento de múltiplas doenças multissistêmicas leva à perda da capacidade adaptativa e ao declínio na funcionalidade. De acordo com a pesquisa da Vigilância de Fatores de Risco e Proteção por Inquérito TelefônicoVIGITEL (MS - MINISTÉRIO DA SAÚDE, 2010), que faz parte do Ministério da Saúde, foi observada a prevalência de hipertensão em $60,2 \%$, obesidade em $19,4 \%$ e diabetes em $22 \%$, dados relativos à população acima de 65 anos, entre homens e mulheres. Além disso, o dado 
relacionado ao sedentarismo populacional representa 13,5\% dos 45 aos 54 anos, $20 \%$ dos 55 aos 64 anos e 36,7\% acima da faixa etária dos 65 anos, considerando indivíduos que não praticaram qualquer atividade física ou lazer nos últimos três meses e que não realizam esforços físicos intensos no trabalho, não se deslocando para ele a pé ou de bicicleta, por no mínimo 10 minutos por dia e que não participam da faxina pesada de suas casas. Desta forma, pesquisas acerca das alterações fisiológicas decorrentes do envelhecimento podem propiciar uma melhor compreensão dos mecanismos que atuam neste processo, possibilitando intervenções preventivas e terapêuticas.

\subsection{O ENVELHECIMENTO E SUA INFLUÊNCIA NOS MECANISMOS FISIOLÓGICOS E BIOLÓGICOS}

As alterações que começam no início da vida adulta, só se tornam importantes e funcionalmente significativas, devido à composição redundante dos sistemas orgânicos, quando o declínio atinge uma extensão considerável ou se associam ao aparecimento de doenças. A velocidade deste declínio depende de diversos fatores genéticos e epigenéticos que determinarão a resposta do organismo aos estímulos (ESQUENAZI; BOIÇA; GUIMARÃES, 2014).

No sistema nervoso central, a perda de volume cerebral durante o envelhecimento é de 2 a $3 \%$ por década depois dos 50 anos de idade, e o peso diminui $8 \%$ comparado ao peso máximo quando adulto. Com o envelhecimento, a perda neuronal está limitada a algumas áreas. No idoso, sem déficits aparentes, no córtex e no cerebelo o número de células permanece o mesmo ao longo da vida. (FREITAS, 2011). O envelhecimento gera mudanças plásticas negativas, pois produz um decréscimo da densidade de espinhos dendríticos e da arborização dendrítica, diminuição dos receptores de glutamato e da neurogênese no hipocampo e diminuição da expressão de fatores neurotróficos. Contudo, as interações entre os efeitos negativos com os aspectos positivos dos processos de plasticidade associados a ambientes enriquecidos e atividade física direcionada tende a ser de grande valia para melhorar as atividades motoras e cognitivas que estão prejudicadas no idoso, enquanto a inatividade e o desuso podem acentuar as alterações estruturais e neuroquímicas, favorecendo o declínio sensorial, motor e cognitivo (GOH; PARK, 2009; HEUNINCKX et al., 2005).

Com o passar dos anos, o sistema cardiovascular também sofre alterações devido às mudanças fenotípicas. Assim, as artérias sofrem uma desordem estrutural e funcional, o aumento da rigidez da parede arterial contribui para que essas alterações ocorram, as artérias 
aumentam de diâmetro e espessura. Após os 60 anos de idade a elasticidade está bem diminuída, aumentando a bioimpedância do fluxo sanguíneo durante a sístole (LAKATTA, 2015). A função pulmonar apresenta redução da capacidade vital, diminuição do volume expiratório forçado, perda da elasticidade do tecido pulmonar, aumento do espaço morto e menor mobilidade da parede torácica (SPIRDUSO, 2005).

O sistema musculoesquelético passa por um processo natural ao longo da vida de remodelagem das unidades motoras representando um processo contínuo, que envolve o reparo e a reconstrução da placa motora terminal. Essa remodelagem progride por desnervação seletiva das fibras musculares, seguida por brotamento terminal dos axônios a partir das unidades motoras adjacentes (MCARDLE, 2008). Esse processo durante o envelhecimento degrada-se, resultando em atrofia muscular por desnervação, particularmente das fibras tipo II, esse processo está associado com a redução no hormônio de crescimento (GH) circulante, no fator-1 de crescimento semelhante a insulina (IGF-1), nas isoformas músculo específicas de IGF e nas estruturas da placa terminal. A redução na área muscular total possui um paralelismo com o tamanho reduzido das fibras, particularmente das fibras de contração rápida nas extremidades inferiores. Aumentando proporcionalmente à área ocupada pelas fibras musculares de contração lenta (tipo I) (FREITAS, 2011).

A seguir são descritas as alterações que ocorrem nas capacidades funcionais no desempenho da força, massa muscular, equilíbrio e mobilidade, assim como a consequência dessas mudanças fisiológicas e biológicas, e como as modalidades de treinamento (resistência elástica e máquinas pneumáticas) podem reduzir esses efeitos.

\subsection{CAPACIDADE FUNCIONAL DURANTE O ENVELHECIMENTO}

De acordo com a Classificação Internacional de Funcionalidade - CIF (ORGANIZAÇÃO MUNDIAL DA SAÚDE, 2004), a capacidade funcional pode ser definida como a capacidade de executar uma tarefa ou uma ação, visando indicar o provável nível máximo de funcionalidade que o indivíduo pode atingir em um dado domínio, em determinado momento e ambiente.

De acordo com Lipsitz (LIPSITZ, 2002), para que um indivíduo realize suas atividades diárias e instrumentais, é necessário que ocorra a integração de redes complexas de sistemas de controle, sistemas de feedback e outros mecanismos de regulação. A interação contínua entre os componentes mecânicos, elétricos e químicos, garante que a informação seja constantemente trocada. Estes processos dinâmicos dão origem a um organismo adaptável e 
resiliente, preparado para responder às perturbações internas e externas. Durante o processo de envelhecimento, as interações dos inputs (entrada de sinais) ocorrem de maneira lenta, irregular, aleatória e simplificada. Consequentemente, ocorre a redução da capacidade funcional que pode levar à síndrome da fragilidade, institucionalização, diminuição da mobilidade, redução da qualidade de vida e morte.

Tratando da capacidade funcional, os atributos físico-funcionais e percepto-cognitivos que são associados, seriam: composição corporal, qualidade muscular, força e potência, desempenho em testes de mobilidade, equilíbrio, visão funcional, cognição associada à tarefa, cognição relacionada à função cognitiva e, por fim, a atenção dividida (PERRACINI; FLÓ, 2011).

\subsection{A REDUÇÃO DA FORÇA MUSCULAR E OS EFEITOS PROVOCADOS PELO TREINAMENTO RESISTIDO}

Durante o passar dos anos, a força muscular é reduzida, de modo que cerca de $15 \%$ dessa redução ocorre após os 50 anos de idade. Aos 70 anos, esse valor dobra a cada década (MOTALEBI; LOKE, 2014). Os processos de atrofia da massa muscular e a redução das fibras musculares são alguns dos fatores responsáveis por esses efeitos (BOTTARO et al., 2007), provocado por uma contração mais duradoura, um relaxamento lento e aumento da fatigabilidade muscular, bem como os fatores neurais levam à redução da excitabilidade, diminuição do recrutamento motor, mudanças na estrutura da actina e miosina (BRIAN CLARK; TODD MANINI, 2011) .

Durante o envelhecimento, a força muscular possui um papel significativo na preservação da capacidade de realizar essas atividades, já que a perda substancial dessa força pode levar ao risco de queda, à dependência física, imobilidades e incapacidades (HÉBERT, 1997; MARIANO et al., 2013). Nos últimos anos, o número de pesquisas e publicações relacionadas ao treinamento resistido para idosos tem aumentado consideravelmente. $\mathrm{O}$ último posicionamento do ACSM, sobre a progressão do treinamento resistido para a população idosa, recomenda iniciar um programa de treino usando máquinas e pesos livres (CHODZKO-ZAJKO et al., 2009).

Os efeitos do treinamento de resistido (TR) são específicos não apenas quanto ao tipo de treinamento, mas quanto à musculatura que está sendo trabalhada e à maneira como está sendo trabalhada. As adaptações que ocorrem incluem aumento da capilarização da musculatura esquelética, aumento dos níveis das enzimas oxidativas da musculatura, redução 
da resistência muscular esquelética, aumento do diâmetro dos vasos sanguíneos (SPIRDUSO, 2005), além de produzir aumento na área da secção transversa, modificações metabólicas, aumento volumétrico das células e constituintes musculares (HUNTER; MCCARTHY; BAMMAN, 2004).

A metanálise de Peterson et al. (PETERSON et al., 2010), demonstrou em 47 estudos, 78 programas de treinamento, totalizando 1.079 idosos saudáveis de ambos os sexos. Nessa pesquisa, foram observadas mudanças significativas na força dos membros inferiores e superiores, comparando pré e pós-intervenção, com diferentes grupos musculares avaliados pelo teste de repetição máxima (1 RM). Os seus achados sugerem que o TR é eficaz para melhorar a força entre idosos, particularmente o treinamento com maior intensidade sendo considerado uma estratégia viável para amenizar os efeitos da perda de força muscular.

De acordo com a revisão sistemática com metanálise de Martins et al. (2013), a resistência elástica provou ser eficaz para melhorar a força muscular em idosos saudáveis. Entre os 11 estudos cujos tamanhos dos efeitos foram utilizados, havia 834 indivíduos com idades entre 60 e 79 anos, contudo, pouca informação estava disponível sobre a intensidade do treino, e foi demonstrada a importância de estabelecer relações de dose-resposta de diferentes intensidades de treinamento sobre a força muscular nessa população. Sendo assim, novos estudos são necessários para identificar métodos viáveis e objetivos da avaliação da força muscular, utilizando materiais elásticos diretamente.

No que diz respeito às máquinas pneumáticas, os efeitos da inércia são reduzidos de modo a permitir maiores velocidades, assim como as forças necessárias para a realização dos movimentos permanecem mais consistentes durante toda a fase concêntrica do exercício, proporcionando uma carga/resistência que não está sujeita à inércia ou impulso, quando comparadas à utilização de pesos livres, levando a uma menor fadiga periférica, principalmente durante um protocolo de hipertrofia muscular, já que não ocorre a desaceleração da carga, a fim de compensar o impulso inicial produzido (FROST; JOHN; NEWTON, 2010; MICHAEL et al., 2008; PELTONEN; HAKKINEN; AVELA, 2013).

De acordo com os autores Fatouros G. Ioannis et al. (2006), os idosos foram divididos em quatro grupos: controle (sem treinamento resistido), intensidade baixa (aproximadamente $40 \%$ de $1 \mathrm{RM}$ ), intensidade moderada (aproximadamente 60\% de $1 \mathrm{RM}$ ) e intensidade alta (aproximadamente $80 \%$ de 1 RM). Os resultados demonstram que a adaptação ao treinamento e destreinamento com relação às variáveis de força e capacidade funcional estão associadas com a intensidade do treinamento realizada, principalmente no grupo acima de 60\% de 1 RM.

Somado a esses resultados, Henwood and Taaffe (2008) demonstraram, através do 
teste de repetição máxima, força isométrica e eletromiografia, que durante o destreinamento de 6 meses, em geral houve queda do desempenho muscular. De acordo com os autores, aparentemente, o treinamento é capaz de gerar ganhos de força muscular. Entretanto, apesar disso, os ganhos não ficaram retidos durante a fase de destreinamento.

\subsection{A PERDA DA MASSA MUSCULAR E AS SUAS CONSEQUÊNCIAS DURANTE O PROCESSO DE ENVELHECIMENTO}

A massa muscular diminui aproximadamente 50\% (dos 20 aos 90 anos) ou 40\% (dos 30 aos 80 anos), há redução da densidade muscular e aumento do conteúdo gorduroso intramuscular (alterações que são mais pronunciadas na mulher do que no homem). Ocorre também a presença da atrofia muscular devido à perda gradativa e seletiva das fibras esqueléticas (sendo a diminuição mais acentuada em fibras musculares do tipo II) (ROSSI, 2008). Estas taxas são mais elevadas em indivíduos sedentários e duas vezes maiores em homens do que nas mulheres. No entanto, os homens, em média, têm maiores quantidades de massa muscular e menor sobrevida do que as mulheres, por isso a sarcopenia é potencialmente uma maior preocupação de saúde pública entre as mulheres do que entre os homens (ROLLAND et al., 2008).

De acordo com a revisão sistemática realizada por Mcgregor et al. (2014), não apenas as alterações na massa muscular, mas outros fatores que sustentam a qualidade do músculo, incluindo a composição, metabolismo, capacidade aeróbia, a resistência à insulina, infiltração gordurosa, fibrose e ativação neural, desempenham um papel importante no declínio da função muscular e na mobilidade reduzida associada ao envelhecimento. Esses fatores sustentam a função da influência muscular na capacidade de gerar força muscular e na mobilidade de acordo com o aumento da idade. Apesar disso, as controvérsias nos estudos demonstram que o impacto do desempenho muscular em comparação ao impacto da baixa massa muscular parece ser mais significativo nos efeitos que atingem o desempenho funcional (VISSER; SCHAAP, 2011).

A redução da massa muscular e a perda da função associada são situações inevitáveis do envelhecimento, no entanto, apesar disso, podem ser minimizadas e até revertidas, com a melhora do condicionamento físico. Sendo assim, os exercícios possuem papel fundamental prevenindo as deficiências musculares relacionadas à idade. 


\subsection{EQUILÍBRIO E MOBILIDADE DURANTE O ENVELHECIMENTO}

O sistema nervoso central produz padrões de atividade muscular necessários para regular a relação entre o centro de massa corporal e a base de suporte, que possui dois objetivos: orientação e equilíbrio postural. Estes ocorrem a partir das interações dinâmicas entre informação sensorial e desempenho muscular (HORAK, B. F., 1997). Entretanto, como já mencionado anteriormente, o processo de envelhecimento acarreta declínios nos sistemas sensoriais (visual, vestibular e somatossensorial), sistema nervoso e sistema motor, comprometendo de maneira direta ou indireta o controle postural (MATSUDO; MATSUDO; NETO, 2000; ROSSI, 2008; SPIRDUSO, 2005).

O equilíbrio, que pode ser classificado, diz respeito às forças que atuam sobre o corpo ao realizar uma determinada posição ou durante a execução dos movimentos. Dessa forma, a manutenção do equilíbrio, busca manter a homeostasia para enfrentar as exigências de situações inesperadas nas quais o organismo é exposto cotidianamente, de forma a sustentar ou alcançar uma orientação desejada (HORAK, B. F., 1997).

No que diz respeito à mobilidade, esta possui vários componentes, por exemplo, agilidade, velocidade e equilíbrio. De acordo com Visser e Schaap (2011), a redução da força nos músculos extensores de joelho pode estar associada à diminuição da mobilidade e consequentemente, ser um fator limitante para o desempenho das AVD's. Dessa maneira, a mobilidade permite ao indivíduo alterar a posição do corpo ou a direção de um movimento, no menor tempo possível, podendo gerar uma maior autonomia na locomoção de acordo com as demandas necessárias (SPIRDUSO, 2005).

As consequências das diferentes modalidades de exercício para a melhora do equilíbrio têm sido amplamente investigadas para minimizar os efeitos deletérios do processo do envelhecimento. Entretanto, ocorrem divergências entre os resultados encontrados, possivelmente devido à variação dos métodos de avaliação e intervenção.

No que diz respeito à avaliação do equilíbrio e os benefícios do exercício físico, de acordo com a revisão sistemática dos autores Howe et al. (2007), o exercício parece gerar efeitos benéficos estatisticamente significativos no equilíbrio em curto prazo. No entanto, a evidência contida nestes ensaios é limitada, principalmente nos pequenos estudos, que demonstraram uma série de deficiências metodológicas, o que restringe a capacidade de comparar ou reunir diferentes ensaios a partir dos quais poderão ser realizadas conclusões firmes em relação à eficácia das intervenções. 
A avaliação do equilíbrio pode ser mensurada de forma direta, pela quantificação da posição do centro de pressão $(\mathrm{CP})$, pela quantidade de oscilações, através do auto relato ou por meio dos testes de habilidades funcionais (mensurações indiretas) (PERRACINI; FLÓ, 2011).

Baseando-se nas discussões acima, os testes escolhidos para a avaliação foram o timed up and go (TUG) e o teste de alcance funcional (TAF). São testes de fácil aplicação, pouca exigência de equipamentos, baixo custo, seguros, dotados de boa confiabilidade e aplicabilidade na área clínica, no exercício físico e no envelhecimento O teste TUG avalia a agilidade e o equilíbrio dinâmico, enquanto o TAF avalia a estabilidade anterior, flexibilidade e mobilidade. Apesar do desempenho muscular ser importante para essas habilidades, outros fatores como coordenação, agilidade e equilíbrio são essenciais para a realização do movimento (DUNCAN PW, WEINER DK, CHANDLER J, 1990; PODSIADLO; RICHARDSON, 1991).

\subsection{TREINAMENTO RESISTIDO REALIZADO COM MÁQUINAS PNEUMÁTICAS E RESISTÊNCIA ELÁSTICA}

O treinamento de resistência foi recomendado, inicialmente, para o ganho de força e hipertrofia muscular em situações específicas. Contudo, ele tem sido recomendado como uma forma coadjuvante para diferentes populações e patologias. Nas últimas décadas, observa-se o crescente esforço para a melhor compreensão das modalidades e os efeitos dos protocolos, apesar disso, existem poucos estudos sobre a resistência elástica e, principalmente, sobre as máquinas de musculação pneumáticas.

Os dispositivos elásticos são portáteis e permitem a sua utilização em quase qualquer lugar. Além disso, oferecem baixo custo e são de fácil manutenção (MARTINS RODRIGUES, 2013; MOTALEBI; LOKE, 2014). A resistência elástica depende da constante (k), do alongamento (x), da característica de cada material elástico polimérico, e não depende da gravidade, sendo assim, proporciona resistência não apenas no plano vertical, mas em toda a gama de movimento e/ou no plano horizontal (MELCHIORRI; RAINOLDI, 2011).

No que diz respeito às máquinas pneumáticas, desenvolvidas em 1978, por Keiser, os equipamentos pneumáticos de resistência (variáveis) foram introduzidos como um estímulo mecânico através do qual a massa corporal do indivíduo representa a única inércia que deve ser superada para iniciar o movimento, portanto, potencialmente oferecendo a oportunidade de desenvolver a energia específica para a velocidade necessária para a realização do 
movimento. Porém, não existem evidências empíricas para suportar tal contenção. De acordo com a literatura, as pesquisas futuras devem colocar mais ênfase na compreensão dessas vantagens e desvantagens mecânicas que são inerentes aos tipos de resistência a serem utilizadas durante o treinamento, de modo a suscitar as maiores melhorias nessa população (FROST; JOHN; NEWTON, 2010; PELTONEN; HAKKINEN; AVELA, 2013). 


\section{MÉTODOS}

\subsection{DELINEAMENTO DO ESTUDO}

O delineamento ensaio clínico aleatorizado foi utilizado neste estudo, no qual as participantes foram selecionadas de maneira aleatória, por randomização em blocos, através de um gerador de números randômicos realizado no programa Microsoft Excel@, a aleatorização foi realizada de maneira cega (MOHER et al., 2012) nos grupos máquinas pneumáticas (GMP) e grupo resistência elástica (GRE). As avaliações foram realizadas em três momentos: avaliação pré-intervenção (PRÉ), avaliação pós-intervenção (PÓS), realizada imediatamente após as 12 semanas de treinamento e avaliação do destreinamento (DES), cujo período de seguimento sem intervenção foi de 10 semanas.

Os procedimentos desse estudo foram aprovados pelo Comitê de Ética da Faculdade de Ciências da Saúde, da UnB, no dia 21 de julho de 2011, protocolo 081/11 (ANEXO A), de acordo com a resolução nº196/96 do Conselho Nacional de Saúde, responsável por regulamentar as pesquisas com seres humanos. A participação no estudo foi voluntária e, após os esclarecimentos dos objetivos, avaliações e intervenções, as participantes foram convidadas a assinarem o Termo de Consentimento Livre e Esclarecido (TCLE) (APÊNDICE A).

\subsection{PARTICIPANTES}

Antes de iniciar o estudo, é importante salientar que foi realizado o cálculo amostral e a amostra apresenta em sua composição, 44 (quarenta e quatro) indivíduos, ou seja, 22 (vinte e dois) indivíduos em cada grupo, no mínimo. Foi calculado, a priori considerando o (a) teste ANOVA de medidas repetidas; (b) 2 grupos; (c) erro tipo I $=5 \%$; (d) erro tipo II $=20 \%$; (e) poder do teste estatístico $=80 \%$; (f) tamanho do efeito $=20 \%$. Este cálculo foi realizado com o programa G Power® versão 3.1.

O recrutamento da amostra foi realizado através da distribuição de panfletos em Centros de Saúde, no Hospital Regional de Ceilândia, igrejas, nos centros de convivência de idosos, através de parcerias com gestores dos centros de saúde e geriatras na cidade de Ceilândia - DF. Em seguida, houve palestras na FCE - UnB, com o intuito de oferecer esclarecimentos sobre o projeto, riscos, benefícios e horários. Ao todo, foram realizadas 5 palestras e após cada uma delas, foram coletados os contatos das interessadas. 


\subsubsection{Critérios de inclusão}

Para participar do programa de treinamento resistido, as voluntárias deveriam ter, no mínimo, 60 anos de idade, residir no Distrito Federal, apresentar atestado médico que as liberassem para a prática de treinamento resistido e não ter realizado esse tipo de treinamento nos 6 meses anteriores.

\subsubsection{Critérios de exclusão}

Foram excluídas as voluntárias que apresentaram doenças crônicas degenerativas (metabólicas, cardiovasculares, mentais, vasculares, reumatologicas e ortopédicas), alterações circulatórias, cirurgias traumato-ortopédicas nos últimos 6 meses, uso de dispositivos de auxílio para a locomoção, restrição da amplitude de movimento devido a traumas ou cirurgias em qualquer articulação do corpo, histórico de fraturas que comprometiam a mobilidade, assim como uso de próteses ou órteses em membros superiores ou inferiores.

\subsection{LOCAL E EQUIPE DE PESQUISADORES}

Os instrumentos das avaliações físicas utilizados nos momentos PRÉ, PÓS e DES, pertencem ao Laboratório de Desempenho Humano da UnB - Campus Ceilândia, Laboratório de Força e Laboratório de Cineantropometria da Faculdade de Educação Física UnB Campus Darcy Ribeiro. Todas as medidas de desfecho e o treinamento foram realizados por duas fisioterapeutas e um educador físico, com o auxílio de estudantes de fisioterapia e educação física. Os treinamentos foram realizados no CEM 04, Campus UnB-Ceilândia.

\subsection{TRIAGEM DOS PARTICIPANTES}

As mulheres idosas que tiveram interesse em participar do estudo foram entrevistadas para a caracterização dos aspectos sociodemográficos, além da elegibilidade dos critérios da amostra segundo o questionário semiestruturado (APÊNDICE B). Esse questionário incluiu os critérios de seleção da amostra e os aspectos gerais de saúde.

De acordo com a divulgação da pesquisa, 113 indivíduos efetivaram contato telefônico ou compareceram à FCE-UnB, apresentando interesse em participar da pesquisa. Entretanto, 
apenas 74 compareceram e foram avaliadas de acordo com os critérios de inclusão. Dessas, 10 foram excluídas pelos critérios de seleção da amostra e 10 desistiram da fase de treinamento devido aos horários, localização ou por falta de interesse.

Foram motivos de exclusão: trombose venosa profunda $n=1$, prática de treinamento resistido $n=1$, insuficiência cardíaca congestiva $n=1$, acidente vascular cerebral $n=2$, artrite reumatoide $n=1$, idade inferior a 60 anos $n=4$. Assim, 54 das mulheres idosas avaliadas para elegibilidade foram selecionadas e distribuídas aleatoriamente nos grupos de pesquisa $n=27$.

Durante o treinamento, $\mathrm{n}=06$ idosas não completaram o treinamento resistido no GRE, os motivos foram: faltaram aos treinamentos $\mathrm{n}=02$, incompatibilidades de horários $\mathrm{n}=01$, acidentes domiciliares com sequelas $n=01$, pneumonia $n=01$ e cirurgia ortopédica $n=01$. No GMP houve apenas uma desistência atribuída à incompatibilidade de horários, finalizando a amostra submetida ao treinamento com $n=26$ mulheres idosas no GMP e $n=21$ mulheres idosas no GRE. Após 10 semanas de destreinamento, durante a avaliação no GRE, houve uma perda atribuída a cirurgia de vesícula biliar. No GMP, as perdas foram: falta de interesse $\mathrm{n}=01$, morte na família $\mathrm{n}=01$, viagem $\mathrm{n}=01$ e outras idosas foram retiradas para fins de análise estatística $n=03$. O número total de idosas em cada grupo foi de 20 mulheres idosas. A seguir, é possível observar na figura 2 o fluxograma da amostra: 
Figura 1. Fluxograma da seleção da amostra

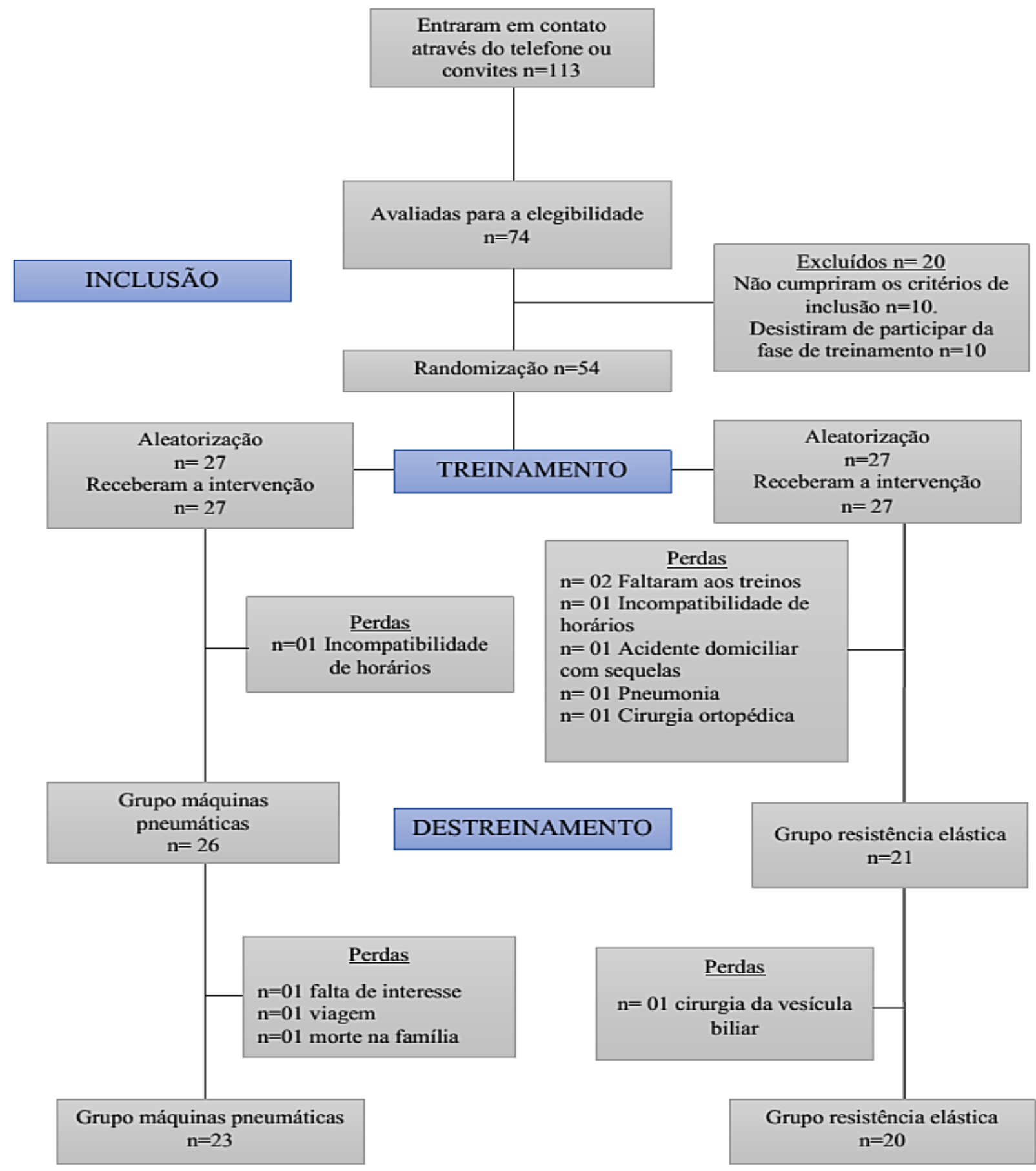

Fonte: Autora, 2016 


\subsection{AVALIAÇÕES ANTROPOMÉTRICAS}

Por uma questão de logística e de demanda dos equipamentos, as participantes foram transportadas até o Laboratório de Cineantropometria e Laboratório de Força, localizados na UnB- FEF. Durante a fase de pré-intervenção para a caracterização inicial dos voluntários, a massa corporal foi mensurada com a utilização de uma balança digital, de resolução em gramas (modelo 2006 pp TOLEDO, Brasil), as voluntárias foram orientadas a utilizar roupas leves e retirar os sapatos e demais acessórios. A estatura foi mensurada utilizando o estadiômetro, com resolução em centímetros (CARDIOMED, Brasil) fixado na parede. O índice de massa corporal (IMC) foi calculado através da divisão da massa corporal pela estatura ao quadrado $\left(\mathrm{Kg} / \mathrm{m}^{2}\right)$.

\subsection{MEDIDAS DE DESFECHOS}

\subsubsection{Avaliação dos testes de mobilidade e equilíbrio}

Durante a realização dos testes, apesar do desempenho muscular ser importante, outras variáveis como agilidade, coordenação, equilíbrio, flexibilidade, mobilidade e marcha, são associadas à função executiva. As escolhas dos testes nesse estudo foram baseadas na praticidade dos mesmos, na validade e na sua reprodutibilidade. Os testes foram realizados no Ginásio terapêutico da Faculdade de Ceilândia- UnB.

\section{a) Timed up and go}

$\mathrm{O}$ teste quantifica em segundos a mobilidade funcional através do tempo que o indivíduo leva para realizar a tarefa, trata-se de um teste útil, prático, rápido que dispensa equipamentos especiais ou de treinamento prévio do pesquisador (PERRACINI; FLÓ, 2011).

A voluntária inicia o teste sentada na cadeira (com a coluna ereta) o mais próximo da borda, com uma perna (dominante) à frente da outra e as palmas das mãos sobre as coxas. A cadeira fica encostada na parede para que não ocorram acidentes na hora da saída. Ao sinal “Atenção, Já!”, a voluntária levanta da cadeira, caminha o mais rapidamente possível, 
contorna um cone e retorna à posição sentada. O cone é posicionado a uma distância de 3 metros da extremidade da cadeira e, como medida de segurança, um espaço de 1 metro depois do cone é demarcado e isolado. A cronometragem será parada somente quando o idoso colocar-se na posição inicial, sentado com as costas apoiadas na cadeira. A variável a ser analisada é o menor tempo percorrido para realização do teste em segundos das três tentativas realizadas (KHAZZANI et al., 2009).

Podsiadlo e Richardson (1991), admitiram como desempenho normal para adultos saudáveis um tempo entre 10 segundos; entre 11 e 20 segundos, considera-se o esperado para idosos frágeis ou com deficiência, os quais tendem a ser independentes na maioria das atividades de vida diária; no entanto, levar acima de 20 segundos para a realização da tarefa sugere prejuízo importante da mobilidade, tornando necessária uma avaliação mais detalhada. Os idosos que realizam o TUG em um tempo maior que 13,5 apresentam maior risco para quedas.

b) Teste de alcance funcional

O teste de alcance funcional (TAF) conhecido internacionalmente como Funcional Reach, é usado para avaliar o alcance funcional, sendo uma medida dinâmica dos limites de estabilidade durante o deslocamento do centro e gravidade dentro da base de sustentação (PERRACINI; FLÓ, 2011).

No teste de alcance funcional, a voluntária está na posição ortostática com coluna ereta, braço em flexão a $90^{\circ}$ e o corpo próximo a parede, onde é fixada uma fita métrica. A partir dessa posição, é solicitado que a voluntária se desloque anteriormente o máximo que consegue sem que as bases fixas dos pés sejam alteradas, mantendo-se dentro dos limites da estabilidade. São realizadas três tentativas e para efeitos de análise, utiliza-se a maior distância em centímetros alcançada nas três tentativas. Duncan et al. (1990) consideraram que aqueles idosos que alcançaram os valores entre $25,4 \mathrm{~cm}$ e $15,2 \mathrm{~cm}$ tiveram 2 vezes mais chances de terem sofrido duas ou mais quedas em 6 meses, quando comparados aqueles que alcançaram $25,4 \mathrm{~cm}$ ou mais, e aqueles que alcançaram $15,2 \mathrm{~cm}$ ou menos tinham 4 vezes mais chances de sofrer duas ou mais quedas em 6 meses. 


\subsubsection{Avaliação da força muscular}

Dentre os métodos para a avaliação da força muscular, encontra-se o dinamômetro isocinético, que aplica uma resistência mecânica em função da força exercida pela pessoa ao movimento articular ao longo de uma determinada amplitude através de um acionamento controlado. As vantagens desse método são prover um mecanismo, seguro e com máxima resistência ao longo de toda a amplitude de movimento, além de permitir a quantificação de torque, potência e trabalho (ERNESTO et. al, 2009). As avaliações foram realizadas no Laboratório de Força da Faculdade de Educação Física - UnB, utilizando o dinamômetro isocinético Biodex System ${ }^{\circledR}$ (modelo III).

A força muscular do membro superior é verificada através do pico de torque da flexão concêntrica do cotovelo (PTC) e a força do membro inferior é verificada pelo pico de torque realizado durante a extensão concêntrica do joelho (PTJ) dominante, respectivamente. $\mathrm{O}$ membro dominante é definido pela preferência de escovar os dentes ou escrever, para o membro superior e a preferência em chutar uma bola no alvo foi determinada para o membro inferior. Os protocolos utilizados para a mensuração da força foram aleatorizados através de sorteio realizado com um programa de computador:

$1^{\circ}$ protocolo: (a) uma série de aquecimento com 10 repetições a $300 \%$; (b) duas séries de quatro repetições a $60 \%$ s; (c) duas séries de quatro repetições a $180 \%$ s.

$2^{\circ}$ protocolo: (a) uma série de aquecimento com 10 repetições a 300\%; (b) duas séries de quatro repetições a $180 \%$ s; (c) duas séries de quatro repetições a $60 \%$ s.

O intervalo de recuperação entre as séries foi de um a dois minutos (BOTTARO; RUSSO; OLIVEIRA, 2005), em que foi utilizado o maior PT nas duas velocidades para fins de análise estatística.

O posicionamento é realizado de acordo com as instruções contidas no manual do fabricante; as idosas são posicionadas de maneira confortável na cadeira do dinamômetro em seguida são fixados os cintos de segurança. São coletadas na fase PRÉ para que possam ser utilizadas as mesmas medidas nos outros momentos do estudo; (a) altura da cadeira; (b) regulagem do encosto; (c) posição da cadeira; (d) posição do dinamômetro; (e) posição do braço de resistência; (f) altura do suporte para os pés; (g) altura do encosto do braço. Todas as voluntárias realizam o protocolo de intervenção para o PT de membro inferior e em seguida o instrumento era regulado e calibrado para realização do teste para PT de membro superior. O teste foi realizado por duas fisioterapeutas e pelo profissional de educação física, com o 
auxílio de estudantes de iniciação cientifica. Foi utilizado o encorajamento verbal e visual para tentar alcançar o nível máximo de esforço.

\subsubsection{Avaliação da massa muscular}

A avaliação da massa muscular por si só não pode explicar totalmente a perda de força muscular e a função física em adultos mais velhos, entretanto, a preservação da mobilidade e das capacidades funcionais depende de múltiplos componentes dos músculos, ossos, tendões, ligamentos e articulações e o comprometimento em qualquer tecido pode resultar em mobilidade reduzida (MCGREGOR; CAMERON-SMITH; POPPITT, 2014). Entretanto, a perda de massa muscular parece preceder a perda de massa óssea, principalmente durante a inatividade física causada pela descarga mecânica, sendo importante observar que a atrofia muscular pode causar a degradação dos ossos (LLOYD et al., 2011).

$\mathrm{O}$ equipamento de Absormetria de raios-X de dupla energia (DEXA) é considerado uma maneira de aferição indireta da composição corporal e padrão ouro, determinando a quantidade de gordura e de massa livre de gordura no corpo (TOOMBS et al., 2012). A massa livre de gordura (MLG) inclui componentes não gordurosos do corpo: músculos, pele, ossos e vísceras. A mensuração é estimada subtraindo-se a massa gorda da massa corporal total, porém a MLG de componentes específicos do corpo também pode ser estimada. A MLG também é conhecida como massa corporal magra, apesar de quantificar também a gordura essencial (SPIRDUSO, 2005).

A mensuração da composição corporal de maneira indireta foi realizada na Faculdade de Educação Física-UnB, com o equipamento de Absormetria de raios-X de dupla energia (DEXA), da marca GE Eletric Company (modelo Lunar Prodigy®). As voluntárias foram posicionadas durante o procedimento de mensuração em decúbito dorsal sobre a mesa do equipamento, conforme instruções do manual Software enCORE®. Os membros inferiores foram posicionados próximos em rotação neutra, envolvidos por duas faixas de velcro e os membros superiores ao lado do corpo, com as palmas das mãos viradas para baixo. Os registros PRÉ, PÓS e DES foram identificados como corpo inteiro com escala em quilogramas. Os indivíduos utilizaram roupas leves, sem calçados e foram orientados a retirar todos os acessórios do corpo. O teste foi realizado por duas fisioterapeutas, com o auxílio de estudantes da iniciação científica. 


\section{INTERVENÇÕES}

\subsection{VARIÁVEIS DE MANIPULAÇÃO DO TREINAMENTO}

A eficácia do treinamento resistivo progressivo consiste na prescrição correta das variáveis manipuláveis (intensidade, frequência, volume, escolha dos exercícios e intervalo de recuperação), incluindo a orientação adequada durante a realização do exercício e o controle do método de progressão.

O volume de treinamento é igual à soma do número total de repetições em cada série, multiplicada pelo número de séries e pela carga utilizada em cada exercício. Sendo assim, cada fase do TRP enfatiza uma adaptação neurofisiológica específica (KRAEMER; ADAMS et al., 2002). Seguindo o modelo clássico de periodização linear, o estudo apresentou uma fase inicial de treinamento com volume alto e com baixas cargas, assim, à medida que o treino progrediu, o volume diminuiu, enquanto que a intensidade aumentou juntamente com o aumento da carga.

De acordo com as recomendações do ACSM, nesse estudo foram escolhidos os exercícios uniarticulares e os pluriarticulares, a fim de promover os ganhos de força e capacidade funcional. A principal característica dos exercícios uniarticulares é o reduzido risco de lesão devido ao recrutamento muscular específico, e os exercícios multiarticulares envolvem ativações neurais e coordenações complexas (KRAEMER; ADAMS et al., 2002).

Consideramos o intervalo de recuperação entre as séries de 1 minuto e o intervalo de descanso entre as sessões de treino foi de 48 horas (ERNESTO; BOTTARO; AL, 2009). Em relação à frequência, as modalidades foram conduzidas duas vezes por semana, com intensidades de moderada a alta. Os equipamentos que utilizamos foram a resistência elástica e as máquinas pneumáticas, nos diferentes grupos. Durante o treinamento resistido progressivo com máquinas pneumáticas e resistência elástica, o protocolo de treino foi o mesmo em ambos os grupos. Na fase de destreinamento, as idosas foram instruídas a abster-se de qualquer forma de treinamento resistido, aeróbio ou estruturado. 


\subsection{PROTOCOLO DE INTERVENÇÃO}

Os exercícios resistidos foram realizados no ginásio terapêutico (máquinas pneumáticas) e na área livre do campus (equipamentos de resistência elástica) da Faculdade da Ceilândia, CEM 04 e executado pelas fisioterapeutas e pelo profissional de educação física.

Todas as participantes passaram por um período de familiarização de duas semanas, em que realizaram duas séries de 15 a 20 repetições em todos os exercícios, utilizando 1 minuto de recuperação e com intensidade de moderada a alta. A carga foi definida nos testes de RM, uma semana antes do início dos treinos (CHODZKO-ZAJKO et al., 2009).

Tanto na fase de familiarização, quanto na intervenção, foram realizados dois treinos semanais com intervalo de 48 horas de descanso entre as sessões. As participantes foram divididas em três turmas no período da manhã. Ao final do programa, cada voluntária realizou 24 sessões de treinamento ou até $75 \%$ dos treinamentos. Diante das faltas, foi proposta a reposição do treinamento, e as voluntárias que faltaram três vezes consecutivas foram eliminadas do projeto. Cada sessão de treino teve duração aproximada de uma hora em ambos os grupos. Os treinos foram compostos por nove exercícios para os grupos máquinas pneumáticas e grupo resistência elástica de acordo com a tabela 1:

Tabela 1. Treinamento resistido realizado nos GRE e GMP, membros superiores e inferiores

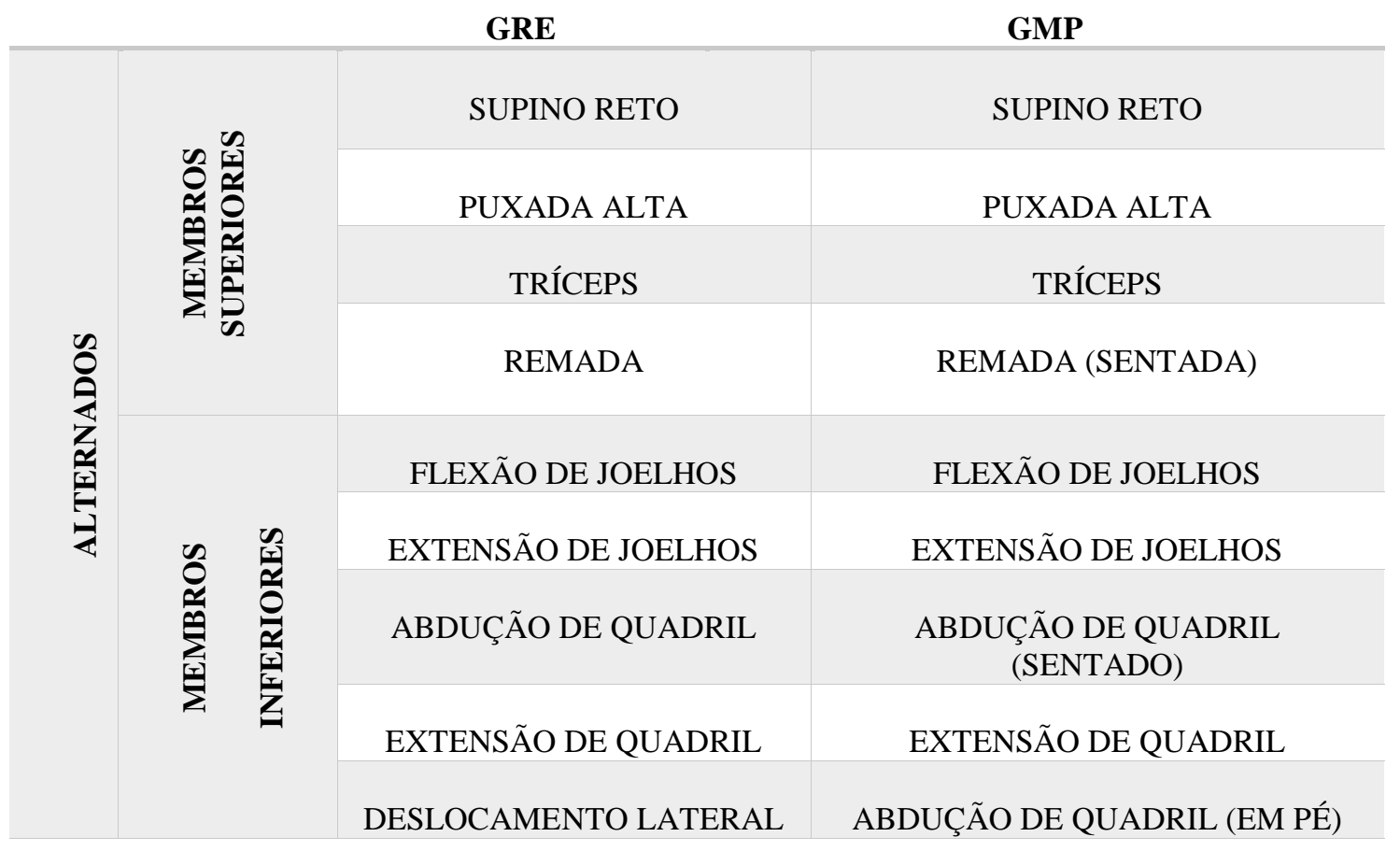

Fonte: Autora, 2016. 
O programa de exercícios teve duração de 12 semanas de treinamento divididas em três mesociclos, cada um teve duração de quatro semanas e foi utilizada a periodização clássica (linear). De acordo com o número de repetições máximas (RM), a progressão da carga foi realizada treinando em todos os ciclos nessa zona de esforço, sendo assim, a intensidade do TR aumenta a carga e reduz o número de repetições. A seguir, na tabela 2, é possível observar a descrição das fases de treinamento.

Tabela 2. Descrição do período de treinamento realizado durante as fases de teste de RM, familiarização e treinamento

\begin{tabular}{c|ccc} 
FASES & SEMANA & SÉRIES & REPETIÇÕES \\
\hline TESTE DE RM & $1^{\mathrm{a}}$ & & \\
FAMILIARIZAÇÃO & $2^{\mathrm{a}} \mathrm{e} 3^{\mathrm{a}}$ & 2 & $15-20$ \\
MESOCICLO I & $4^{\mathrm{a}} \mathrm{e} 7^{\mathrm{a}}$ & 3 & $12-15$ \\
MESOCICLO II & $8^{\mathrm{a}} \mathrm{a} 11^{\mathrm{a}}$ & 3 & $10-12$ \\
MESOCICLO III & $12^{\mathrm{a}} \mathrm{a} 15^{\mathrm{a}}$ & 3 & $10-8$
\end{tabular}

Fonte: Autora, 2016.

\section{3 EQUIPAMENTOS UTILIZADOS E A PROGRESSÃO DE CARGAS}

\subsubsection{Resistência elástica e máquinas pneumáticas}

A desvantagem da resistência elástica reside no fato de que nem todos os materiais elásticos proporcionam tensões similares (SANTOS et al., 2009). As suas propriedades mecânicas e o conhecimento sobre elas são fundamentais, resultando na necessidade de definir as diferenças nas cores para a execução de uma intervenção adequada.

No equipamento de resistência elástica, o material depende do percentual de estiramento e da espessura do tubo, sendo que os exercícios propostos foram realizados no momento inicial com $0 \%$ e momento final de $150 \%$ de estiramento. Os momentos iniciais e finais dos exercícios foram delimitados com a régua de percentual de estiramento que acompanha o kit do material e que contêm quatro diferentes alongamentos dos tubos (50\%, $100 \%, 150 \%$ e $200 \%$ ). Desta maneira, as participantes executam os exercícios até que a ADM final atinja o alongamento de $150 \%$ do equipamento elástico (MARTINS et al., 2014), essas 
delimitações foram realizadas com cones e hastes e serviram de referências ao longo do período de treinamento.

Os tubos apresentam sete níveis crescentes de resistência, representados por cores (amarelo, vermelho, verde, azul, preto, roxo e ouro). Para aumentar a intensidade do exercício de forma a ajustar os valores, a cor utilizada é substituída pela cor seguinte da escala de resistência, por exemplo, passando do tubo elástico verde, para o azul (Figura 3). Para os indivíduos que alcançarem a cor de maior resistência $\left(7^{\circ}\right.$ nível $=$ ouro), outro tubo é acrescentado, seguindo sempre a ordem de progressão (ex: ouro + amarelo).

Além desses equipamentos, alças de mão foram utilizadas para a realização dos exercícios de supino, puxada e remada alta, barra de mão para o exercício de tríceps, alças de tornozelo para os exercícios de flexão e extensão de joelhos, abdução e extensão de quadril e acessório e-loop para realização do deslocamento lateral. Foram utilizadas ainda marcações no chão através do uso de cones, réguas para o controle de estiramento dos tubos elásticos, para o controle da carga.

No GMP, o aumento de carga foi realizado no Display das máquinas pneumáticas, esse aumento foi suficiente para que a carga ideal do número de RM alvo fosse atingida. $\mathrm{O}$ aumento de carga é no mínimo $0,5 \mathrm{~N}$ ou mais, até que a voluntária não consiga realizar nenhuma repetição a mais do que aquela solicitada. A determinação da intensidade da carga já havia sido realizada por meio do monitoramento do número de repetições máximas alvo para cada mesociclo de treino. Nas duas semanas que antecederam o período de treinamento, foi realizada a familiarização, 2 séries de 15 a 20 RM, e a cada mesociclo o número de repetições diminuiu, havendo também o aumento da carga.

A progressão da carga foi realizada de acordo com o número de RM alvo com a maior carga possível para atingir esse número, a intensidade do TR progrediu ao longo das semanas, de acordo com o aumento da carga e a diminuição do número de repetições para que a zona alvo de repetições fosse atingida. Desta maneira, sempre que a participante realizasse a quantidade superior de repetições máximas que havia sido estipulada para a zona alvo de acordo com a fase de treinamento, uma carga adicional era acrescentada em ambos os grupos.

Durante todo o protocolo, as participantes foram encorajadas a executar a maior amplitude do movimento possível, velocidade cadenciada e confortável em cada repetição. As Figuras de 2 a 10, no ANEXO B, demonstram os exercícios realizados por cada grupo com a utilização da resistência elástica progressiva ou máquinas pneumáticas. 


\section{ANÁLISE ESTATÍSTICA}

A análise estatística foi realizada pela empresa Quantimais, que não estava envolvida com a pesquisa. A suposição de normalidade foi testada em todas as variáveis através do teste de Shapiro-Wilk. Para a análise do comportamento dos grupos ao longo dos tempos, foi utilizado o teste ANOVA de medidas repetidas $(2 \times 3)$ e, para cumprir a condição de esfericidade dos dados, foi utilizada a correção Greenhous e Geisser, de forma que todos os resultados foram considerados não significativos a um nível de significância de 5\% (FIELD, 2011). Adotando-se o critério de Cohen para classificar o tamanho do efeito, considerando, insignificante <0,19; pequeno de: 0,20-0,49; médio; 0,50-0,79; grande; 0,80-1,79; muito grande; >1,30 (ESPÍRITO-SANTO; DANIEL, 2015). 


\section{RESULTADOS}

\subsection{CARACTERÍSTICAS DOS PARTICIPANTES}

Vinte participantes finalizaram o destreinamento em cada grupo. No GMP, com médias de idade de $67.5 \pm 5.18$ anos (variando de 60 a 75 anos), altura de $1.53 \pm 0.065$ (variando de 1.42 a 1.67 metros), massa corporal de $67.96 \pm 11.24$ (variando de 54 a $100 \mathrm{~kg}$ ) e IMC de $29.03 \pm 4.42 \mathrm{Kg} / \mathrm{m}^{2}$ (variando de 23.92 a $32.07 \mathrm{Kg} / \mathrm{m}^{2}$ ). No GRE, com médias de idade de $66.1 \pm 4.72$ anos (variando de 60 a 77 anos), altura de $1.55 \pm 0.073$ (variando de 1.43 a 1.75 metros), massa corporal de $69.62 \pm 10.14$ (variando de 51 a $89.4 \mathrm{~kg}$ ) e IMC de $28.89 \pm$ $3.48 \mathrm{Kg} / \mathrm{m}^{2}$ (variando de 20.95 a $37.05 \mathrm{Kg} / \mathrm{m}^{2}$ ) suas características antropométricas estão descritas na tabela abaixo:

Tabela 3. Características antropométricas dos participantes dos GMP e GRE

\begin{tabular}{ccc}
\hline & GMP $(\mathbf{n}=\mathbf{2 0})$ & GRE $(\mathbf{n}=\mathbf{2 0})$ \\
\hline Idade $($ anos $)$ & $67.5 \pm 5.18$ & $66.1 \pm 4.72$ \\
Altura $(\mathbf{m})$ & $1.53 \pm 0.065$ & $1.55 \pm 0.073$ \\
Massa corporal $(\mathbf{K g})$ & $67.96 \pm 11.24$ & $69.62 \pm 10.14$ \\
IMC $\left(\mathbf{k g} / \mathbf{m}^{\mathbf{2}}\right)$ & $29.03 \pm 4.42$ & $28.89 \pm 3.48$ \\
\hline
\end{tabular}

Fonte: Autora 2016 


\subsection{MEDIDAS DE DESFECHO}

Tabela 4. Resultados das medidas de desfecho, médias, desvio padrão e tamanho do efeito.

\begin{tabular}{|c|c|c|c|c|c|c|c|c|c|c|c|}
\hline Variáveis & $\begin{array}{c}\text { Grupos } \\
(\mathbf{n}=20)\end{array}$ & \multicolumn{3}{|c|}{ PRÉ } & \multicolumn{3}{|c|}{ Pós } & TDE & \multicolumn{3}{|c|}{ DES } \\
\hline \multicolumn{12}{|c|}{ Equilíbrio e mobilidade } \\
\hline \multirow{2}{*}{ TUG (s) } & GMP & 6.43 & \pm & $0.81 *$ & 5.38 & \pm & $0.58 *$ & 1.00 & 5.51 & \pm & 0.56 \\
\hline & GRE & 6.36 & \pm & $0.83^{*}$ & 5.53 & \pm & $0.56^{*}$ & 0.83 & 5.33 & \pm & 0.67 \\
\hline \multirow{2}{*}{ TAF $(\mathbf{c m})$} & GMP & 36.40 & \pm & $4.05^{*}$ & 38.53 & \pm & $2.94^{*}$ & 0.35 & 38.35 & \pm & 2.96 \\
\hline & GRE & 37.58 & \pm & 4.08 & 38.65 & \pm & 3.91 & 0.21 & 39.10 & \pm & 2.88 \\
\hline \multicolumn{12}{|l|}{ Força Muscular } \\
\hline \multirow{2}{*}{ PTC 60\% /s (N.m) } & GMP & 23.36 & \pm & $5.65^{*}$ & 27.31 & \pm & $5.39 *$ & 0.51 & 25.11 & \pm & $6.86^{*}$ \\
\hline & GRE & 25.63 & \pm & $7.47 *$ & 28.81 & \pm & $6.08 *$ & 0.33 & 25.49 & \pm & $4.40^{*}$ \\
\hline \multirow{2}{*}{ PTC $180^{\circ} / \mathbf{s}$ (N.m) } & GMP & 20.51 & \pm & $4.64^{*}$ & 24.99 & \pm & $4.38^{*}$ & 0.70 & 22.29 & \pm & $5.46^{*}$ \\
\hline & GRE & 22.33 & \pm & $7.64 *$ & 24.54 & \pm & 5.22 & 0.24 & 21.53 & \pm & $4.33^{*}$ \\
\hline \multirow{2}{*}{ PTJ 60\% $/$ (N.m) } & GMP & 89.46 & \pm & $20.79 *$ & 101.2 & \pm & 16.49 & 0.44 & 93.35 & \pm & $18.98 *$ \\
\hline & GRE & 93.00 & \pm & $15.75^{*}$ & 101.7 & \pm & 16.62 & 0.38 & 92.64 & \pm & $15.91 *$ \\
\hline \multirow{2}{*}{ PTJ $180^{\circ}$ /s (N.m) } & GMP & 60.58 & \pm & $10.22 *$ & 66.95 & \pm & 11.27 & 0.41 & 62.49 & \pm & $10.51 *$ \\
\hline & GRE & 59.10 & \pm & $12.61 *$ & 66.65 & \pm & 13.45 & 0.42 & 62.01 & \pm & $13.39 *$ \\
\hline \multicolumn{12}{|l|}{ Massa livre de gordura } \\
\hline \multirow{2}{*}{ MLGS (Kg) } & GMP & 3.87 & \pm & 0.68 & 3.89 & \pm & 0.67 & 0.01 & 4.06 & \pm & 1.14 \\
\hline & GRE & 4.04 & \pm & 0.60 & 4.01 & \pm & 0.59 & 0.03 & 4.03 & \pm & 0.59 \\
\hline \multirow{2}{*}{ MLGI (Kg) } & GMP & 10.96 & \pm & 1.39 & 10.92 & \pm & 1.24 & 0.02 & 10.94 & \pm & 1.24 \\
\hline & GRE & 11.26 & \pm & $1.39 *$ & 11.60 & \pm & $1.52 *$ & 0.16 & 11.42 & \pm & 1.45 \\
\hline \multirow{2}{*}{ MLGT (Kg) } & GMP & 36.06 & \pm & 4.78 & 36.23 & \pm & 4.87 & 0.03 & 36.01 & \pm & 4.73 \\
\hline & GRE & 36.72 & \pm & 4.04 & 37.06 & \pm & 4.06 & 0.06 & 36.72 & \pm & 3.42 \\
\hline
\end{tabular}

Legenda:, GMP= grupo máquinas pneumáticas, GRE= grupo resistência elástica, PRÉ= Avaliação inicial, $\mathrm{PÓS}=$ treinamento, $\mathrm{DES}=$ destreinamento, $\mathrm{TUG}=$ Timed up and go, $\mathrm{TAF}=$ teste de alcance funcional, $\mathrm{PTC}=$ Pico de torque de cotovelo na velocidade, PTJ=Pico de torque de joelho, MLGS= Massa livre de gordura membros superiores, MLGI= Massa livre de gordura membros inferiores, MLGT=Massa livre de gordura total, TDE $=$ Tamanho do efeito, $*=$ Valores significantes $\mathrm{p}<0,05$.

Fonte: Autora, 2016. 
a) Timed up and go

As análises no Grupo Máquinas Pneumáticas (GMP) demonstraram redução no tempo de execução do teste nas fases PRÉ e PÓS $(F=59.932 ; G L=1 ; p=0.000)$. Não foram encontradas diferenças durante o período de DES ( $F=0.395 ; G L=0.757 ; p=0.395)$. Os valores no Grupo Resistência Elástica (GRE) demonstraram diferenças significativas nas fases PRÉ e PÓS $(F=28.174 ; G L=1 ; p=0.000)$. Não foram encontradas diferenças durante o DES $(F=2.365 ; G L=1 ; p=0.141)$. Os resultados indicam que ambas as modalidades foram capazes de promover a melhora no equilíbrio dinâmico.

b) Teste de alcance funcional

Foram encontradas mudanças estatísticas no GMP $(F=7.910 ; G L=1 ; p=0.011)$, e não foram encontradas mudanças durante o DES ( $F=0.090 ; G L=1 ; p=0.767)$. No GRE não foram encontradas mudanças estatísticas em nenhuma das fases $(F=1.292 ; G L=2 ; p=0.287)$.

c) Força muscular

\section{Membros inferiores}

De acordo com as análises relativas ao GRE, a força muscular nos membros inferiores apresentou mudanças significantes nas velocidades de $60 \%$ s $(F=17.618 ; G L=1 ; p=0.000)$ e, durante o DES, houve perdas $(F=15.665 ; G L=1 ; p=0.001)$, assim como na velocidade de $180^{\circ}$ s $(F=22.084 ; G L=1 ; p=0.000)$, em que também ocorreram perdas durante o DES $(F=16.155 ; G L=1 ; p=0.001)$. No GMP, a análise demonstrou que houve mudanças estatísticas na velocidade de $60^{\circ}$ s $(F=26.027 ; G L=1 ; p=0.000)$ e durante a fase de DES, perdas dos ganhos obtidos $(F=19.092 ; G L=1 ; p=0.000)$. Na velocidade de $180^{\circ} / \mathrm{s}$, houve modificações $(F=26.586 ; G L=1 ; p=0.000)$ e durante o DES, perdas $(F=41.186 ; G L=1$; $p=0.000)$. 
De acordo com as análises estatísticas no GMP, a força muscular nos membros superiores, na velocidade de $60^{\circ} \mathrm{s}$, apresentou diferenças significantes $(F=16.064 ; G L=1$; $p=0.001)$, de modo que na fase de DES houve perdas $(F=8.985 ; G L=1 ; p=0.007)$. A velocidade de $180^{\circ}$ /s também demonstrou mudanças estatísticas ( $\left.F=18.160 ; G L=1 ; p=0.000\right)$, assim como durante o DES ( $F=13.593 ; G L=1 ; p=0.002)$.

No GRE, houve mudanças na velocidade de $60 \%$ s $(F=7.632 ; G L=1 ; p=0.012)$ e perdas durante o DES $(F=18.263 ; G L=1 ; p=0.000)$. A velocidade de $180^{\circ} / \mathrm{s}$ não demonstrou mudanças estatísticas $(F=2.782, G L=1 ; p=0.112)$ e, apesar disso, o DES apresentou perdas $(F=30.616, G L=1, p=0.000)$.

d) Massa livre de gordura

\section{Membros superiores}

A análise demonstrou não haver mudanças estatísticas no GMP em nenhuma das fases $(F=0.719 ; G L=1.118 ; p=0.421)$, assim como no $\operatorname{GRE}(F=0.171, G L=1.64, p=0.802)$.

\section{Membros inferiores}

A análise dos dados demonstrou não haver mudanças estatísticas no GMP em nenhuma das fases $(F=0.025 ; G L=1.91 ; p=0.972)$, enquanto no GRE, ocorreram mudanças estatísticas $(F=15.537 ; G L=1 ; p=0.001)$. Durante o DES não houve mudanças $(F=1.549$; $G L=1 ; p=0.228)$.

e) Massa livre de gordura total

A MLGT não demonstrou diferenças no $\operatorname{GMP}(F=0.640 ; G L=1.995 ; p=0.533)$, assim como no GRE $(F=1.331 ; G L=1.771 ; p=0.276)$. 


\section{DISCUSSÃO}

O objetivo deste estudo foi avaliar os efeitos dos exercícios resistidos, realizados com máquinas pneumáticas e com resistência elástica, em idosas saudáveis, a partir de nove exercícios para membros superiores e inferiores. Os treinos foram realizados duas vezes por semana e as medidas de desfecho foram testes de equilíbrio e mobilidade, força e massa muscular, durante as fases de pré (avaliação inicial), pós (12 semanas) e destreinamento (10 semanas).

Os resultados demonstraram que ambas as intervenções não apresentam diferenças estatísticas entre si. Particularmente, foi encontrada uma redução estatística no tempo de execução do teste TUG em ambos os grupos e não houve perdas durante o destreino. No TAF, apenas o GMP apresentou ganhos.

A massa livre de gordura apresentou ganhos no GRE nos membros inferiores e não houve perda durante o destreino. Referente à força muscular, os dados do GMP e do GRE apresentaram ganhos nos membros inferiores em ambas as velocidades, entretanto, as 10 semanas de DES apresentam perdas estatísticas. O GMP apresentou ganhos nos membros superiores em ambas as velocidades e perdas estatísticas durante o DES. O GRE apresentou diferenças estatísticas na velocidade de $60 \%$ s e não houve mudanças durante o DES.

\subsection{TESTES DE MOBILIDADE E EQUILÍBRIO}

De acordo com o presente estudo, é possível observar que as 12 semanas de treinamento causaram redução no tempo de realização do teste TUG, que necessita das habilidades de agilidade e equilíbrio. O tamanho do efeito foi de 1,00 ( $\mathrm{p}=0.000)$ no GMP, foi de 0,83 ( $\mathrm{p}=0.000$ ) no GRE considerado um efeito grande. O teste é combinado por uma série de componentes, incluindo levantar-se, caminhar, mudar de direção e sentar-se, atividades que são executadas habitualmente (RIKLI \& JONES, 1999). Apesar dos testes indiretos serem menos sensíveis a essas modificações relacionadas a oscilações de desempenho, sugere-se que com o aumento das atividades motoras e a melhora da força muscular, os incrementos na realização dessa tarefa foram possíveis.

No que diz respeito ao teste de alcance funcional, os resultados foram significantes apenas no GMP com o tamanho do efeito considerado pequeno de 0,35. No GRE os resultados não foram significantes. $O$ teste demonstra a flexibilidade e a mobilidade do 
indivíduo, além de determinar o quanto o idoso é capaz de se deslocar dentro do limite de estabilidade anterior (DUNCAN PW, WEINER DK, CHANDLER J, 1990).

A origem das adaptações neurais que os idosos apresentam em resposta ao treinamento de resistência, ficam comprometidas devido à degradação progressiva do sistema neuromuscular, em particular à degeneração dos neurônios motores da coluna vertebral, a perda das fibras corticoespinhais e a degeneração cerebelar. Esses fatores, por sua vez, influenciam na velocidade em que as adaptações do treinamento provocam na melhora do desempenho em tarefas diárias que exigem movimentação (PERRACINI; FLÓ, 2011).

Nesse sentido, apesar de apresentar ganhos na força muscular, nem sempre os exercícios resistidos conseguem causar ganhos nas habilidades funcionais (BARRY; CARSON, 2004). De acordo com Latham et al. (2004), em sua revisão sistemática com metanálise, que incluiu 66 artigos com 3.783 participantes idosos, o treinamento com resistência não apresenta de forma clara, benefícios e efeitos significativos no equilíbrio de idosos. O tema ainda é controverso, pois, alguns autores encontraram uma melhora de equilíbrio após o treinamento resistido, enquanto que outros reportam que o treinamento resistido não promove melhora estatística.

Com relação aos padrões de normalidade apresentados na variável TAF, a literatura mostra que os idosos que alcançaram entre $15,2 \mathrm{~cm}$ e 25,4 tinham 2 vezes mais chances de cair do que aqueles que alcançaram $>25,4 \mathrm{~cm}$. Aqueles que alcançaram $<15,2 \mathrm{~cm}$ tinham 4 vezes mais chances de cair (DUNCAN PW, WEINER DK, CHANDLER J, 1990). Em nosso

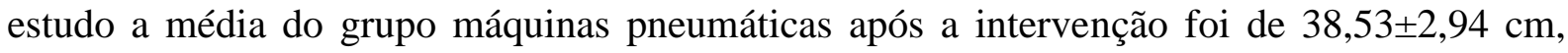
demonstrando que de acordo com esses valores de referência, as idosas possuem menos riscos de quedas.

Os achados não estatísticos na variável TAF no GRE, apesar dessa modalidade permitir um maior ganho de movimentos, devido ao fato que durante o treinamento as voluntárias ficaram mais restritas à força que era exigida com os estiramentos do material. Outro fator seria que as participantes eram mulheres idosas saudáveis e independentes fisicamente, que apresentam níveis mais altos de funcionalidade do que a população como um todo (RIKLI \& JONES, 2008).

Apesar disso, de acordo com o estudo piloto realizado por Motalebi e Loke (2014), no qual foi efetuado o treinamento com a resistência elástica com idosos (média de idade $69.2 \pm$ 4.62 anos), durante 12 semanas e frequência de 3 vezes, nota-se que obtiveram um ganho de $27.1 \%$ no TUG e $15.3 \%$ no TAF, esses resultados divergem na variável TAF, visto que não obtivemos mudanças estatísticas no GRE e apresenta resultado semelhante na variável TUG. 
Sousa et al (2005) também encontraram diferenças significativas $(\mathrm{p}<0.05)$ para o TAF com $13 \%$ de aumento na distância alcançada no teste nas medidas pré e pós, em um programa de treinamento de força progressivo em idosos considerados sadios. Os resultados indicam que o treinamento de força de alta intensidade promove melhorias na estabilidade anterior, resultado de adaptações neuronais e também por um treinamento com velocidades de execução de movimentos mais lentas.

É importante salientar que a estabilidade corporal envolve a coordenação de estratégias sensórias-motoras para estabilizar o centro de massa do corpo dentro da base de sustentação durante perturbações iniciadas pelo próprio indivíduo (marcha, transferências posturais movimento intencional, de segmentos do corpo) e em relação a perturbações externas (empurrão, escorregão, tropeço etc.) para que a estabilidade possa ser mantida (POLLOCK, 2000).

Os exercícios que foram realizados em pé nas sessões de treinamento, necessitavam constantemente de equilíbrio e de ajustes posturais que são importantes para promover a estabilidade corporal necessária ou mecanismos antecipatórios e compensatórios (FREITAS, 2011; HORAK, B. F., 1997).

De acordo com Fleck et al. (2000), exercícios multiarticulares requerem maior tempo de fase neural e de aprendizagem inicial em relação aos exercícios monoarticulares. No caso do GRE, essas adaptações motoras específicas podem ter ido além do período de familiarização, tendo em vista o curto período de treinamento. E as alterações provocadas pelo envelhecimento, podem ter influenciado, como tempo de latência nos músculos posturais aumentado, atraso no tempo de reação ao preparar o movimento voluntário, ativação dos músculos posturais após a ativação do motor primário do movimento (HORAK, F. B., 2006; SHUMWAY-COOK, ANNE WOOLLACOTT, 2010).

Os protocolos de capacidade funcional e de potência, que executam atividades como transferência de carga, subir e descer escadas, bem como tarefas que podem ser realizadas com o aumento da carga e/ou velocidade e aumento da potência, têm mostrado que os idosos podem melhorar significativamente o seu desempenho funcional através desta forma de treinamento, que pode ser mais eficaz do que o treinamento de força (BEAN et al., 2004; EARLES; JUDGE; GUNNARSSON, 2001).

Outros autores sugerem ainda que o declínio de desempenho durante o envelhecimento é específico à tarefa e é determinado de forma seletiva pelo desuso das funções sensório-motoras. Já aquelas funções que continuam a ser realizadas com o avanço da 
idade, tendem a se manter relativamente estáveis. Intervenções que inserem atividades motoras da vida diária para indivíduos idosos fortalecem essa interpretação (MAHANT \& STACY, 2001).

No que diz respeito à fase de destreinamento, Henwood e Taaffe (2008) investigaram os efeitos do destreino durante um período de 24 semanas, para desenvolvimento da força e da potência muscular em idosos variando de 65-84 anos, avaliando a funcionalidade nos testes de caminhada de 400 metros, 6 minutos e o teste de subir degraus. Apesar do tempo prolongado de destreino, eles observaram o comportamento de preservação dessa funcionalidade, sugerindo que as mudanças devido a períodos mais longos de destreinamento dependem dos exercícios anteriores realizados, da condição física e do estado da população.

Fatouros et al. (2006) demonstraram em seu trabalho que os efeitos do destreinamento na agilidade estão diretamente relacionados à intensidade do treinamento e à duração do destreinamento, observando que o grupo que treinou com maiores intensidades retiveram os efeitos durante 36 semanas e o grupo que treinou com menores intensidades, apresentaram queda significativa da agilidade a partir de 12 semanas (FATOUROS G. IOANNIS et al., 2006). Os nossos resultados não demonstraram mudanças estatísticas no destreinamento, apesar de observarmos uma variação durante as 10 semanas de destreino em ambos os grupos.

\subsection{FORÇA MUSCULAR}

No que diz respeito à força muscular, no GMP, observou-se que nos membros superiores, a força aumentou na velocidade de $60 \%$ ( $=0.001$, TDE $=0.51)$ e na velocidade de $180 \%$ s ( $\mathrm{p}=0,000, \mathrm{TDE}=0.70$ ), o tamanho do efeito foi médio. No GRE houve uma diferença significativa na velocidade de $60 \% \mathrm{~s}(\mathrm{p}=0.0012$, TDE $=0.33$ ), o tamanho do efeito foi pequeno.

No GRE, os exercícios de membros superiores foram realizados em pé, sendo assim as idosas necessitaram manter a estabilidade do corpo, realizar ajustes compensatórios e antecipatórios, além de realizar os movimentos sem suporte; em contraste ao GMP, que realizavam os exercícios sentados, com equipamentos e suportes mais estruturados. $\mathrm{Na}$ literatura, foram poucos os estudos que avaliaram o decréscimo da força muscular em idosas por meio do PT isocinético em flexores de cotovelo. Frontera et al., (1991) avaliou o PT isocinético nas velocidades de $60 \%$ e $180 \%$ s para grupos de 45-54 anos e 65-78 anos e observou que havia uma diminuição de $17 \%$ e $21 \%$ na força absoluta entre essas faixas etárias.

A análise dos membros inferiores no GMP demonstrou ter ocorrido ganhos de força 
muscular na velocidade de $60 \% \mathrm{~s}(\mathrm{p}=0.000 ; \mathrm{TDE}=0.44)$ e na velocidade de $180 \% \mathrm{~s}(\mathrm{p}=0.000$; $\mathrm{TDE}=0.41$ ). No GRE, os resultados demonstraram diferença na velocidade de $60 \% \mathrm{~s}$ $(\mathrm{p}=0.000 ; \mathrm{TDE}=0.38)$ e na velocidade de $180^{\circ} / \mathrm{s}(\mathrm{p}=0.000 ; \mathrm{TDE}=0.42) . \mathrm{O}$ tamanho do efeito foi considerado médio em ambos os grupos e velocidades. A dificuldade da comparação com outros estudos deve-se a falta de padronização na aplicação dos testes e da variedade de velocidade utilizada.

A velocidade angular de $60 \%$ é utilizada em alguns estudos como variável de força muscular. E as velocidades mais altas como a de $180 \%$ s são usadas para obter valores de potência muscular. O maior desempenho do pico de torque encontrado nas velocidades baixas se deve ao fato de que quanto menor a velocidade angular testada, maior o tempo de contração necessário para se vencer a resistência imposta pelo equipamento; sendo assim, maior a tensão muscular e maior a quantidade de fibras musculares envolvidas, necessitando de mais força (ANTERO-JACQUEMIN et al., 2012).

Em estudo realizado por Chandler et al. (1998), durante 10 (dez) semanas, em que foram utilizadas bandas elásticas e realizada a análise do ganho da força nos membros inferiores em idosos frágeis, com idade média de 77.6 \$7,6 anos, (Grupo experimental n = 50 e Grupo controle $\mathrm{n}=50$ ), num período de três vezes por semana, foram realizados cinco exercícios de membros inferiores (extensão e abdução de quadril; extensão e flexão de joelho; flexão do tornozelo) com duas séries de dez repetições cada exercício. Os ganhos do treinamento no PT isocinético de extensão do joelho a $60 \%$ so grupo experimental foi estatisticamente maior que no grupo controle, apesar desses efeitos terem sido similares aos nossos, o tamanho da amostra era maior $(\mathrm{n}=100)$.

O estudo de Mikesky et al. (1994), cujo objetivo foi investigar a eficácia da adesão de 12 semanas de treinamento de resistência progressiva elástica em idosos com a média de idade de 71.2 anos, aleatorizados (grupo controle $n=31$ e grupo experimental $n=31$ ), os testes pré e pós incluíram testes no isocinético de força muscular de joelho, medidas da flexibilidade do quadril, joelho e tornozelo. O grupo experimental treinou três vezes por semana, de uma a três séries, de 10-12 repetições para cada 12 exercícios. Os resultados demonstraram que houve um aumento de $12 \%$ no PT excêntrico de extensão de joelho e na velocidade de $60^{\circ}$, com isso, este valor foi similar ao ganho do presente estudo e o tempo de intervenção igual.

A revisão sistemática de Martins Rodrigues (2013) foi realizada para identificar ensaios clínicos controlados com resultados de parâmetros de força muscular na resistência elástica. Entre os 11 estudos que foram utilizados na metanálise, havia 834 indivíduos com idades entre 60 e 79 anos. Os treinamentos de resistência com elásticos mostraram fortes 
efeitos sobre a força muscular em os idosos saudáveis e aqueles com alguma incapacidade funcional, bem como um efeito moderado sobre a força muscular em idosos doentes. A conclusão foi de que o treinamento com resistência elástica provou ser eficaz para melhorar a força muscular em idosos.

No estudo de Jette et al., (1999) que envolveu 108 indivíduos no GE, foi demonstrado um ganho total da força muscular isométrica dos membros inferiores (extensão de quadril, abdução de quadril, extensão de joelho) de $12 \%$ após 24 semanas de treinamento. Colado et $a l$. , (2010) em seu estudo que comparou os ganhos de força entre máquinas convencionais e resistência elástica obteve ganhos equivalentes nos dois grupos estudados também, porém, seu estudo foi conduzido com mulheres jovens durante 8 semanas de treinamento, sendo que, para avaliar a variável força foi utilizada a força máxima de contração isométrica.

Outra metanálise realizada na população idosa também demonstrou efeitos positivos sobre o ganho de força muscular. Na revisão de Peterson et al., (2010), no qual foram verificados os efeitos do treinamento tradicional com pesos sobre a força muscular em idosos

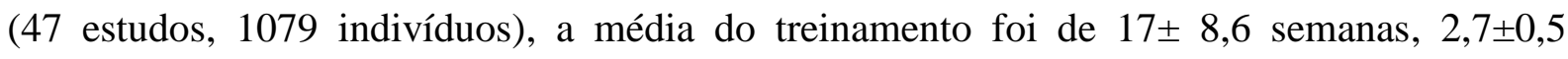
sessões por semana, duração de 8,3 $\pm 2,3$ anos, repetições de $10 \pm 2,6$ vezes, intensidade de $70 \% \pm 12,7$ de 1 RM e média de intervalo de descanso de $110 \pm 25$ segundos. Um efeito positivo para cada um dos resultados de resistência foi determinado no entanto, houve heterogeneidade entre os estudos. O aumento da força variou de 9,8 a 31,6 kg e as variações percentuais foram de $29 \pm 2 \mathrm{~kg}$ para leg press, $24 \pm 2 \mathrm{~kg}$ para supino, $33 \pm 3 \mathrm{~kg}$ extensão do joelho e $25 \pm 2 \mathrm{~kg}$ para puxada. O estudo considerou que os exercícios resistidos são eficazes para melhorar a força entre idosos, particularmente com maior intensidade de treinamento. Sugeriram, portanto, que os exercícios resistidos podem ser considerados uma estratégia viável para evitar a fraqueza muscular generalizada associada ao envelhecimento.

A melhora da força muscular dos membros inferiores distribui de maneira mais equilibrada as forças nos músculos extensores e flexores dos membros inferiores (quadril e joelho), contribuindo para um padrão melhor durante a marcha, visto que o declínio da força muscular é um dos fatores para as quedas em idosos e para a perda da sua autonomia (ESQUENAZI; BOIÇA; GUIMARÃES, 2014; NETTO, 2007). Dessa maneira, para que os programas de treinamento e de reabilitação sejam efetivos, deve-se considerar a capacidade em atingir as zonas alvos do sistema neuromuscular, para que os resultados sejam estendidos para a realização das atividades de vida diária. Sendo assim, torna-se importante observar que 
apesar do treinamento aumentar a força muscular, pode não ser capaz de aumentar as habilidades funcionais (CARROLL; RIEK; CARSON, 2002).

Além disso, sugere-se que o treinamento com resistência elástica seja mais eficaz em indivíduos saudáveis e com limitações funcionais e menos eficaz em indivíduos com algum tipo de transtorno, propondo, dessa maneira, que outros estudos possam estabelecer relações de dose-resposta de diferentes intensidades de treinamento sobre a força muscular em idosos, assim como novos estudos necessários para identificar métodos viáveis e com melhores objetivos de avaliação da força muscular, equilíbrio e massa muscular.

No que diz respeito ao destreinamento, houve uma diferença estatística nos membros superiores, no GMP, na velocidade de $60 \%$ s $(\mathrm{p}=0.007)$ e na velocidade de $180 \% \mathrm{~s}(\mathrm{p}=0.002)$. Nos membros inferiores, na velocidade de $60 \%$ apresentou diferenças significantes $(\mathrm{p}=0.000)$ e na velocidade de $180 \%$ s $(\mathrm{p}=0.000)$. Os resultados são similares às perdas nos membros superiores do GRE, na velocidade de 60\% (p=0.000). Nos membros inferiores, os valores foram significantes nas velocidades de $60 \%(\mathrm{p}=0.001)$ e na velocidade de $180 \%$ s. $(\mathrm{p}=0.000)$.

O estudo de Raso et al. (2001) demonstrou que os membros inferiores preservaram de maneira mais eficiente a capacidade de manutenção da força muscular após a interrupção do treinamento resistido $(22,9$ a $71,9 \%)$ do que os membros superiores $(-14,8$ a 16,1\%). O maior declínio parece ter ocorrido após a oitava semana de destreinamento, entretanto, de acordo com os nossos resultados, os ganhos não foram mantidos nos membros superiores e inferiores em ambos os grupos. A intensidade da carga pode ter sido subestimada no início do estudo, o que influenciou na manutenção desses ganhos.

O envelhecimento influência de maneira negativa o destreinamento, principalmente em idosos com mais de 75 anos, quando comparados aos idosos de 60-73 anos, e apresenta maior prejuízo nas variáveis de força muscular, capacidade funcional e equilíbrio, principalmente quanto mais longo é o destreinamento (TORAMAN, 2005).

A frequência semanal de treinamento, a duração dos diferentes programas de exercícios, que variaram entre 8 e 24 semanas, o tipo de treinamento resistido realizado (hidroginástica, pesos livres, elásticos e equipamentos de musculação) e a intensidade, podem ter influência na dimensão do destreinamento (CARVALHO; MARQUES; MOTA, 2009; FATOUROS G. IOANNIS et al., 2006; TORAMAN, 2005). 


\subsection{MASSA LIVRE DE GORDURA}

A redução da massa muscular e a perda da função associada são situações inevitáveis do envelhecimento, apesar disso, podem ser minimizadas e até revertidas com a melhora do condicionamento físico. Sendo assim, os exercícios possuem papel fundamental, prevenindo as deficiências musculares relacionadas à idade.

No presente estudo foi encontrada uma diferença estatística na variável de massa livre de gordura nos membros inferiores do GRE ( $\mathrm{p}=0,001$; TDE=0.16). $\mathrm{O}$ tamanho do efeito da intervenção é considerado não significante e a fase de destreinamento não apresentou perdas estatísticas.

No GMP não houve mudanças que fossem estatísticas em nenhuma das fases. Não encontramos diferenças significativas intergrupos após o período de treinamento, as outras variáveis de MLG não demonstraram qualquer tendência de aumento em ambos os grupos. De acordo com Flecker (2006), o ganho de massa muscular pode acontecer em programas de treinamento de curta duração em idosos, entretanto, para ser mais efetivo necessita que uma alta carga de treinamento seja imposta (PETERSON et al., 2010).

De acordo com a revisão sistemática realizada por Mcgregor et al. (2014), não apenas as alterações na massa muscular, mas, outros fatores que sustentam a qualidade do músculo, incluindo a composição, metabolismo, capacidade aeróbia, a resistência à insulina, infiltração gordurosa, fibrose e ativação neural, desempenham um papel importante no declínio da função muscular e na mobilidade reduzida associada ao envelhecimento. Esses fatores sustentam a função da influência muscular na capacidade de gerar força muscular e na mobilidade de acordo com o aumento da idade.

Segundo o estudo realizado por Hunter et. al (2004), o aumento da massa muscular em idosos pode começar a ocorrer a partir de nove semanas com o treinamento resistido. Além comprimento das fibras musculares, a hipertrofia muscular parece depender de padrões de recrutamento de fibras musculares, isto é, quando o treinamento de alta carga é realizado as fibras do tipo II têm um maior potencial para o crescimento muscular, por unidade do que as fibras do tipo I.

Taaffe et al. (2009), pautaram sua pesquisa através da realização da tomografia computadorizada das regiões do quadríceps e isquiotibiais, cuja amostra era constituída de 13 indivíduos (sendo 7 homens e 6 mulheres) com média de idade de 70,8 $\pm 1,5$ anos. O estudo teve a duração de 60 semanas e, no prazo de 24 semanas, os indivíduos foram submetidos ao treinamento resistido; 24 semanas de destreinamento e, por fim, nas últimas 12 semanas, o 
retreinamento. $\mathrm{O}$ treinamento consistia de 3 séries de 8 repetições, na frequência de 2 vezes na semana. Os achados desta pesquisa comprovaram que a gordura teve um acréscimo significativo no destreinamento; contudo, a massa muscular progrediu no treinamento, reduziu no destreinamento e tornou a aumentar no retreinamento.

De acordo com Geirsdottir et al., (2011), cuja amostra foi de $n=237$ idosos, variando a média de idade de 62-70 anos, ambos os sexos e 12 semanas de treinamento resistido, com um protocolo de treinamento de 3 séries, 3 vezes por semana, 6-8 repetições utilizando de $75-80 \%$ de 1RM, é possível observar que foram capazes de aumentar a média da massa livre de gordura (média $0,8 \mathrm{~kg} \mathrm{p}<0,001$ ), assim como a força muscular, habilidades físicas e a qualidade de vida. Apesar do estudo não possuir grupo controle, de acordo com os autores, essa não seria uma limitação, esses podem ser devido ao maior número amostral, além de uma adequada determinação da carga.

Em outro estudo sobre MLG, Martins et al. (2015) apresenta sua pesquisa realizada com 40 idosos que foram randomizados em dois grupos de 20 indivíduos cada: Grupo Controle ( $\mathrm{GC}=66,2 \pm 6,6$ anos) e Grupo Experimental ( $\mathrm{GE}=69,1 \pm 6,3$ anos), no qual o treinamento com resistência elástica foi realizado duas vezes por semana, durante 8 semanas e o grupo controle não recebeu qualquer intervenção específica. Os resultados não demonstraram efeitos significativos, intra e inter grupos, nas variáveis de MLGS ( $p=0,19$, $\mathrm{TDE}=0,1)$ e para MLGI $(p=0,88$, TDE $=0,02)$. Esses resultados são semelhantes ao nosso estudo. Considerando as características do treinamento utilizado no presente estudo e a revisão de literatura, podemos interpretar que, o curto período de treino foi associado a um controle de sobrecarga não representativo, fatores importantes a serem considerados para a explicação da ausência de diferença. 


\section{LIMITAÇÕES DO ESTUDO}

Considerando os resultados, recomendamos futuras investigações de maior duração, com um maior controle do destreinamento e com maior número de indivíduos. Além disso, não houve controle das atividades externas realizadas pelas participantes, apenas foi solicitado às idosas que não realizassem nenhum tipo de treinamento resistido além do realizado na pesquisa e que mantivessem as atividades cotidianas. 


\section{CONSIDERAÇÕES FINAIS}

Os achados evidenciaram que a realização desses exercícios resistidos promovem uma redução no tempo de execução do teste TUG em ambos os grupos, e que as idosas retiveram esses ganhos durante a fase de destreino. O GMP apresentou ganhos na variável TAF. A massa livre de gordura apresentou, no GRE, ganhos nos membros inferiores e não houve perda durante o destreino.

Referente à força muscular, os dados do GMP e do GRE apresentaram ganhos nos membros inferiores em ambas as velocidades, entretanto, com as 10 semanas de DES, apresentam perdas estatísticas. O GMP apresentou ganhos nos membros superiores nas duas velocidades e perdas estatísticas durante o DES; o GRE apresentou diferenças estatísticas na velocidade de $60 \%$ s e não houve mudanças durante o DES. Apesar dessas particularidades encontradas os grupos não apresentam diferenças estatísticas entre si, novos estudos são necessários, devido ás limitações desse estudo como controle da carga, período de maior intervenção e controle do destreinamento. 


\section{REFERÊNCIAS}

ANTERO-JACQUEMIN, J. D. S. et al. Comparação da função muscular isocinética dos membros inferiores entre idosos caidores e não caidores. Fisioterapia e Pesquisa, v. 19, n. 1, p. 39-44, 2012.

BARRY, B. K.; CARSON, R. G. The consequences of resistance training for movement control in older adults. The journals of gerontology. Series A, Biological sciences and Journals of gerontology., v. 59, n. 7, p. 730-754, 2004.

BEAN, J. F. et al. Increased Velocity Exercise Specific to Task ( InVEST ) Training: A Pilot Study Exploring Effects on Leg Power, Balance, and Mobility in Community-Dwelling Older Women. European Journal of Applied Physiology, p. 799-804, 2004.

BOTTARO, M. et al. Effect of high versus low-velocity resistance training on muscular fitness and functional performance in older men. European Journal of Applied Physiology, n. 99, p. 257-264, 2007.

BOTTARO, M.; RUSSO, A.; JACÓ DE OLIVEIRA, R. The effects of rest interval on quadriceps torque during an isokinetic testing protocol in elderly. Journal of Sports Science and Medicine, v. 4, n. 3, p. 285-290, 2005.

BRIAN CLARK; TODD MANINI. Functional Consequences of Sarcopenia and Dynapenia in the Elderly. Current Opinion in Clinical Nutrition and Metabolic Care., p. 1-9, 2011.

CARROLL, T. J.; RIEK, S.; CARSON, R. G. The sites of neural adaptation induced by resistance training in humans. The Journal of physiology, v. 544, p. 641-652, 2002.

CARVALHO, M. J.; MARQUES, E.; MOTA, J. Training and detraining effects on functional fitness after a multicomponent training in older women. Gerontology, v. 55, n. 1, p. 41-48, 2009.

CHANDLER, J. M.; DUNCAN, P. W.; KOCHERSBERGER, G. Is lower extremity strength gain associated with improvements in physical performance and disability in frail community dwelling elders? Archives Physical Medicine and Rehabilitation, v. 79, p. 24-30, 1998.

CHODZKO-ZAJKO, W. J. et al. Exercise and physical activity for older adults. Medicine and Science in Sports and Exercise, v. 41, n. 7, p. 1510-1530, 2009.

COLADO, C. J.; N., T. T. Effects of short-term resistance program using elastic bands versus weight machines for sedentary middle-aged women. Journal of Strength and Conditioning Research, v. 22, n. 5, p. 1441-1448, 2008.

COLADO, J. C. et al. A Comparison of Elastic Tubing and Isotonic Resistance Exercises. Sports Medicine, 2010. 
DE VREEDE, P. L. et al. Functional tasks exercise versus resistance exercise to improve daily function in older women: A feasibility study. Archives of Physical Medicine and Rehabilitation, v. 85, n. 12, p. 1952-1961, 2004.

DUNCAN PW, WEINER DK, CHANDLER J, S. S. Functional Reach. A New Clinical Measure of Balance. Journal of Gerontology., 1990.

EARLES, D. R.; JUDGE, J. O.; GUNNARSSON, O. T. Velocity Training Induces PowerSpecific Adaptations in Highly Functioning Older Adults. Archives of physical medicine and rehabilitation, v. 82, n. July, p. 872-878, 2001.

ERNESTO, C.; BOTTARO, M.; AL, E. Efeitos de diferentes intervalos de recuperação no desempenho muscular isocinético em idosos performance among older adults. Revista Brasileira de Fisioterapia, v. 13, n. 1, p. 65-72, 2009.

ESPÍRITO-SANTO, H.; DANIEL, F. Calcular e apresentar tamanhos do efeito em trabalhos científicos: As limitações do $\mathrm{p}<0,05$ na análise de diferenças de médias de dois grupos. Revista Portuguesa de Investigação Comportamental e Social, v. 1, n. 1, p. 3-16, 2015. ESQUENAZI, D.; BOIÇA, S. R.; GUIMARÃES, M. A. M. Aspectos fisiopatológicos do envelhecimento humano e quedas em idosos. Revista Hospital Universitário Pedro Ernesto, v. 13, n. 2, p. 11-20, 2014.

FATOUROS G. IOANNIS et al. Resistance training and detrainig effects on flexibility performance in the elderly are intensity-dependent. Journal of Strength and Conditioning Research, v. 20, n. 3, p. 634-642, 2006.

FREITAS, E. V. DE. Tratado de geriatria e gerontologia. $3^{\mathrm{a}}$. ed. Rio de Janeiro, Guanabara Koogan: $3^{\mathrm{a}}$ edição, São Paulo 2011.

FRONTERA, W. R. et al. A cross-sectional study of muscle strength and mass in 45- to 78yr-old men and women. Journal of applied physiology, v. 71, n. 2, p. 644-650, 1991.

FROST, M. D.; JOHN, C.; NEWTON, U. R. A Biomechanical evalution of resistence.pdf. Sports Medicine, 2010.

GEIRSDOTTIR, O. G. et al. Physical function predicts improvement in quality of life in elderly icelanders after 12 weeks of resistance exercise. The journal of nutrition, health \& aging, v. 16, n. 1, p. 62-66, 2011.

GERAGE, A. et al. Impact of 12 weeks of resistance training on physical and functional fitness in elderly women. Revista Brasileira de Cineantropometria e Performance Humana, v. 15, n. April, p. 145-154, 2013.

GOH, J.; PARK, D. C. Neuroplasticity and cognitive aging. Restor Neurol Neurosci, v. 27, n. 5, p. 391-403, 2009. 
GRAGNOLATI, M. et al. Envelhecendo em um país mais velho (sumário executivo). Revista Portal de Divulgação. [S.l: s.n.], 2012. v. 2. p. 64.

HANSON, E. D. et al. Effects of Strength Training on Physical Function: Influence of Power, Strength, and Body Composition. Journal Strength Cond Res, v. 23, n. 9, p. 2627-2637, 2009.

HÉBERT, R. Functional decline in old age. Canadian Medical Association journal, v. 157, n. 8, p. 1037-45, 1997.

HENWOOD, T. R.; TAAFFE, D. R. Detraining and retraining in older adults following longterm muscle power or muscle strength specific training. The journals of gerontology. Series A, Biological sciences and medical sciences, v. 63, n. 7, p. 751-758, 2008.

HEUNINCKX, S. et al. Neural Basis of Aging: The Penetration of Cognition into Action Control. The Journal of Neuroscience, v. 25, n. 29, p. 6787-6796, 2005.

HORAK, B. F. Clinical assessment of balance disorders. Gait and Posture, v. 6, n. 1, p. 7684, 1997.

HORAK, F. B. Postural orientation and equilibrium: What do we need to know about neural control of balance to prevent falls? Age and Ageing, v. 35, n. SUPPL.2, p. 7-11, 2006.

HOSTLER, D. et al. Skeletal muscle adaptations in elastic resistance-trained young men and women young men and women. European Journal of Applied Physiology, n. January, 2001.

HOWE, T. E. et al. Exercise for improving balance in older people. Cochrane Database of Systematic Reviews, n. 4, 2007.

HUNTER, G. R.; MCCARTHY, J. P.; BAMMAN, M. M. Effects of Resistance Training on Older Adults. Sports Medicine, v. 34, n. 5, p. 329-348, 2004.

INSTITUTO BRASILEIRO DE GEOGRAFIA E ESTATÍSTICA. Censo demográfico 2010. Disponível em: 〈www.censo2010.ibge.gov.br〉.

JETTE, A. et al. Exercise It's Never Too Late: The Strong-for-LifeProgram. American journal of public health, v. 89, p. 66-72, 1999.

KHAZZANI, H. et al. The relationship between physical performance measures, bone mineral density, falls, and the risk of peripheral fracture: a cross-sectional analysis. BioMed Central Public Health, v. 9, p. 297, 2009.

KREBS, D. E.; SCARBOROUGH, D. M.; MCGIBBON, C. A. Functional vs. strength training in disabled elderly outpatients. American journal of physical medicine \& rehabilitation / Association of Academic Physiatrists, v. 86, n. 2, p. 93-103, 2007.

LAKATTA, E. G. So! What' s aging? Is cardiovascular aging a disease ? Journal of 
Molecular and Cellular Cardiology, v. 83, p. 1-13, 2015.

LANDI, F. et al. Exercise as a remedy for sarcopenia. Current Opinion in Clinical Nutrition and Metabolic Care, p. 7, 2013.

LANG, T. et al. Sarcopenia: etiology, clinical consequences, intervention, and assessment.

Osteoporosis international : a journal established as result of cooperation between the European Foundation for Osteoporosis and the National Osteoporosis Foundation of the USA, v. 21, n. 4, p. 543-559, 2010.

LATHAM, N. K. et al. Systematic Review of Progressive Resistance Strength Training in Older Adults. Journal of Gerontology: Medical Sciences, v. 59, n. 1, p. 48-61, 2004.

LIPSITZ, L. A. Dynamics of Stability: The Physiologic Basis of Functional Health and Frailty. Journal of Gerontology: Biological Sciences, v. 57, n. 3, p. 115-125, 2002.

LLOYD, A. S. et al. Interpendence of muscle atrophy and bone loss induced by mechanical unloading. Journal Bone Miner Res, v. 72, n. 2, p. 181-204, 2011.

LOPES, G. L.; SANTOS, M. I. DE O. Funcionalidade de idosos cadastrados em uma unidade da Estratégia Saúde da Família segundo categorias da Classificação Internacional de Funcionalidade. Revista Brasileira de Geriatria e Gerontologia, v. 18, n. 1, p. 71-83, 2015. MARIANO, E. R. et al. Força muscular e qualidade de vida em idosas. Revista brasileira Geriatria e Gerontologia, v. 16, p. 805-811, 2013.

MARTINS RODRIGUES, W. Elastic resistance training to increase muscle strength in elderly : A systematic review with meta-analysis. Archives of gerontology and geriatrics, v. 57, p. 8-15, 2013.

MARTINS, W. R. et al. Effects of short term elastic resistance training on muscle mass and strength in untrained older adults: a randomized clinical trial. BioMed Central geriatrics, v. 15, p. 99, 2015.

MARTINS, W. R. et al. Mechanical evaluation of elastic tubes used in physical therapy. Physiotherapy theory and practice, v. 30, n. 3, p. 218-22, 2014.

MATSUDO, S. M.; MATSUDO, V. K. R.; NETO, T. L. D. B. Impacto do envelhecimento nas variáveis antropométricas, neuromotoras e metabólicas da aptidão física. Revista Brasileira Ciência e Movimento, v. 8, n. 4, p. 21-32, 2000.

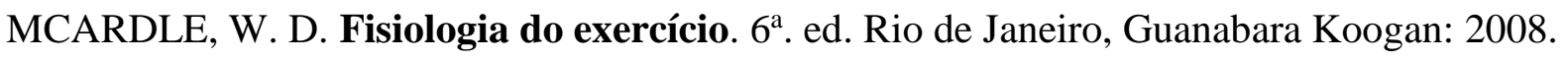
MCGREGOR, R. A.; CAMERON-SMITH, D.; POPPITT, S. D. It is not just muscle mass : a review of muscle quality, composition and metabolism during ageing as determinants of muscle function and mobility in later life. Longevity \& Healthspan 2014, p. 1-8, 2014. MELCHIORRI, G.; RAINOLDI, A. Muscle fatigue induced by two different resistances: 
Elastic tubing versus weight machines. Journal of Electromyography and Kinesiology, v. 21, n. 6, p. 954-959, 2011.

MICHAEL, D. et al. A comparison of the kinematics, kinetics and muscle activity between pneumatic and free weight resistance. European Journal of Applied Physiology, p. 937956, 2008.

MIKESKY, A. E. et al. Efficacy of a home-based training program for older adults using elastic tubing. European Journal of Applied Physiology and Occupational Physiology, v. 69, n. 4, p. 316-320, 1994. Disponível em: 〈http://link.springer.com/10.1007/BF00392037>. MOHER, D. et al. CONSORT 2010 explanation and elaboration: Updated guidelines for reporting parallel group randomised trials. International Journal of Surgery, v. 10, n. 1, p. 28-55, 2012.

MOTALEBI, S. A.; LOKE, S. C. Efficacy of progressive resistance tube training in community dwelling older adults: A pilot study. International Journal of Gerontology, v. 8, n. 4, p. 213-218, 2014.

MS - MINISTÉRIO DA SAÚDE. Estimativas sobre frequência e distribuição sociodemográfica de fatores de risco e proteção para doenças 97 crônicas nas capitais dos 26 estados brasileiros e no Distrito Federal em 2010.

NERI, A. L.; YASSUDA, M. S.; CACHIONI, M. Velhice bem sucedida aspectos afetivos e cognitivos. $3^{\text {a }}$. ed. São Paulo, Campinas: [s.n.], 2004.

NETTO, M. P. Tratado de Gerontologia. 2a . ed. São Paulo, Editora Atheneu: [s.n.], 2007.

ORGANIZAÇÃO MUNDIAL DA SAÚDE. Classificação Internacional de Funcionalidade, Incapacidade e Saúde. EDUSP ed. São Paulo: [s.n.], 2004. ORGANIZAÇÃO MUNDIAL DA SAÚDE -OMS. Good health adds life to years Global brief for World Health Day 2012. p. 28, 2012.

PELTONEN, H.; HAKKINEN, K.; AVELA, J. Neuromuscular responses to different resistance loading protocols using pneumatic and weight stack devices. Journal of Electromyography and Kinesiology, v. 23, n. 1, p. 118-124, 2013.

PERRACINI, M. R.; FLÓ, M. C. Funcionalidade e envelhecimento. Rio de Janeiro, Guanabara: $1^{\mathrm{a}}$ edição, Rio de janeiro, 2011.

PETERSON, M. D. et al. Resistance exercise for muscular strength in older adults: A metaanalysis. Ageing Research Reviews, v. 9, n. 3, p. 226-237, 2010.

PODSIADLO, D.; RICHARDSON, S. The Timed "Up \& Go": A Test of Basic Functional Mobility for Frail Elderly Persons. Journal of the American Geriatrics Society, v. 39, n. 2, p. 142-148, 1991. 
POLLOCK, A. S. . What is balance? Clin Rehabil, v. 14, n. 4, p. 402-406, 2000.

RICE, J.; KEOGH, J. W. L. Power Training: Can it Improve Functional Performance in Older Adults? A Systematic Review The Importance of Functional. International Journal of Exercise Science, 2008.

RICE, J.; KEOGH, J. W. L. Power Training: Can it Improve Functional Performance in Older Adults? A Systematic Review. International journal of exercise science, v. 2, n. 2, p. 131$151,2009$.

ROLLAND, Y. et al. Sarcopenia: its assessment, etiology, pathogenesis, consequences and future perspectives. The journal of nutrition, health \& aging, v. 12, n. 7, p. 433-50, 2008. ROSSI, E. Envelhecimento do sistema osteoarticular Revista Einstein, v. 6, n. Supl 1, p. $7-$ 12, 2008.

SANTOS, G. M. et al. Avaliação mecânica da resistência de faixas elásticas. Revista Brasileira de Fisioterapia, v. 13, n. 6, p. 521-526, 2009.

SHUMWAY-COOK, ANNE WOOLLACOTT, M. H. Controle motor: Teoria e aplicações

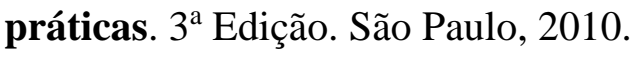

SOUSA, N.; SAMPAIO, J. Effects of progressive strength training on the performance of the functional reach test and the timed get-up-and-go test in an elderly population from the rural north of Portugal. American Journal of Human Biology, v. 17, n. 6, p. 746-751, 2005.

SPIRDUSO, W. W. Dimensões do Envelhecimento. 1a . ed. Barueri, São Paulo: [s.n.], 2005.

TOOMBS, R. J. et al. The impact of recent technological advances on the trueness and precision of DXA to assess body composition. Obesity (Silver Spring, Md.), v. 20, n. 1, p. 30-9, 2012.

TORAMAN, N. F. Short term and long term detraining: is there any difference between young-old and old people? Br J Sports Med, p. 561-565, 2005.

VISSER, M.; SCHAAP, L. A. Consequences of sarcopenia. Clinics in Geriatric Medicine, v. 27, n. 3, p. 387-399, 2011.

WILSON, J. et al. Practical Guidelines and Considerations for the Use of Elastic Bands in Strength and Conditioning. National Strength and Conditioning Association, v. 36, p. 1-9, 2014.

WONG, LAURA RODRÍGUEZ; MOREIRA, M. DE M. Envelhecimento E Desenvolvimento Humano: As Transformações Demográficas Anunciadas Na América Latina (1950-2050) . VI REUNIÓN NACIONAL DE INVESTIGACIÓN DEMOGRÁFICA EN MÉXICO: Balance y Perspectivas de la Demografía Nacional ante el Nuevo Milenio., 2000.

$\mathrm{ZECH}$, A. et al. Residual effects of muscle strength and muscle power training and detraining 
on physical function in community-dwelling prefrail older adults : a randomized controlled trial. BiomedCentral Geriatrics, v. 12, n. 1, p. 1, 2012. 


\section{APÊNDICE A - TERMO DE CONSENTIMENTO LIVRE E ESCLARECIDO}

O (a) Senhor (a) está sendo convidado (a) a participar do projeto: "Efeitos do treinamento resistido no desempenho muscular de idosos comunitários". O objetivo desta pesquisa é: verificar se os exercícios com dispositivos de resistência elástica e com as máquinas pneumáticas podem aumentar a força e a massa muscular em idosos sedentários. Espera-se que os exercícios elásticos e os exercícios nas máquinas possam aumentar a força, massa muscular e melhorar o equilíbrio dos membros superiores e inferiores, como ocorre nos exercícios com máquinas de musculação.

O (a) senhor(a) receberá todos os esclarecimentos necessários antes e no decorrer da pesquisa e lhe asseguramos que seu nome não aparecerá sendo mantido o mais rigoroso sigilo através da omissão total de quaisquer informações que permitam identificá-lo(a). Em relação aos procedimentos da pesquisa, caso o Senhor (a) não tenha um atestado médico próprio para a prática de exercícios resistidos, o Senhor (a), deverá passar por uma consulta médica para avaliar sua saúde hoje e no passado. Caso seja necessário, podemos indicar um médico para tal avaliação, o qual poderá de acordo com a necessidade recomendar exames complementares para o coração com intuito de atestar sua aptidão física para participar de exercícios. No entanto, se for do seu interesse, essa avaliação poderá ser feita com seu cardiologista particular, que deverá lhe fornecer um atestado médico.

A sua participação será através da realização do treino resistido envolvendo a realização de 03 (três) testes: $\left(1^{\circ}\right)$ avaliação do nível de atividade física, $\left(2^{\circ}\right)$ avaliação da mobilidade funcional essa etapa poderá durar de 01 (um) a 02 (dois) dias. Com o término dessa etapa de avaliação tem início a fase de exercícios com o chamado período de familiarização, que consistirá de duas semanas de exercícios leves. Depois dessas 02 (duas) semanas, Senhor (a) realizará mais 12 semanas de exercícios com nível de esforço progressivo. A fase de exercícios será realizada sempre as segundas e quartas feiras, ou terças e quintas, no período matutino. Será realizado um sorteio eletrônico para definir de qual grupo o Sr.(a) fará parte, grupo elástico ou máquina. A avaliação da força muscular dos membros, a capacidade funcional e o controle postural na $14^{\mathrm{a}}$ semana de exercícios. Considerando o total de (28) dias de exercícios (12 semanas efetivas após familiarização), o senhor (a) (necessitará comparecer no mínimo em (25) sessões de exercício, podendo assim ter no máximo 3 (três) faltas.

Esse projeto será realizado no Ginásio terapêutico localizado na QNN 14 Área Especial, Guariroba, Ceilândia Sul (Antiga Faculdade de Ceilândia) e na data combinada, com um tempo estimado de duas horas para sua realização. $\mathrm{O}$ (a) senhor(a) receberá todos os esclarecimentos necessários antes e no decorrer da pesquisa e lhe asseguramos que seu nome não aparecerá sendo mantido o mais rigoroso sigilo através da omissão total de quaisquer informações que permitam identificá-lo(a).

Informamos que o(a) Senhor(a) pode se recusar a responder (ou participar de qualquer procedimento) qualquer questão que lhe traga constrangimento, podendo desistir de participar da pesquisa em qualquer momento sem nenhum prejuízo para o(a) senhor(a). Não há despesas pessoais para o participante em qualquer fase do estudo, incluindo exames e consultas. Também não há compensação financeira relacionada à sua participação. Os resultados da pesquisa serão divulgados nos Centros de Saúde e em eventos e revistas científicas nacionais ou internacionais. Os dados e materiais utilizados na pesquisa ficarão sob a guarda do pesquisador por um período de no mínimo cinco anos, após isso serão destruídos ou mantidos na instituição.

Se o(a) Senhor(a) tiver qualquer dúvida em relação à pesquisa, por favor telefone para:

Dr. Wagner Rodrigues Martins, professor adjunto do Curso de Fisioterapia da Faculdade 
UnB Ceilândia, telefone: (61) 9943-3865 ou com a discente de mestrado e fisioterapeuta Milene Soares (61) 85953870.Este projeto foi Aprovado pelo Comitê de Ética em Pesquisa da Faculdade de Ciências da Saúde da Universidade de Brasília. As dúvidas com relação à assinatura do TCLE ou os direitos do sujeito da pesquisa podem ser obtidas através do telefone: (61) 3107-1947 ou do e-mail cepfs@unb.br. Todas as folhas deverão ser rubricadas pelo Sr.(a) ou responsável e pelo pesquisador responsável. Este documento foi elaborado em duas vias, uma ficará com o pesquisador responsável e a outra com o sujeito da pesquisa.

Nome / assinatura

Pesquisador Responsável/Nome e assinatura

Brasília, de de 


\section{APÊNDICE B - QUESTIONÁRIO PARA IDENTIFICAÇÃO INICIAL DOS CRITÉRIOS DE SELEÇÃO DA AMOSTRA}

Nome: Data:

Telefone: Idade:

Código para preenchimento das perguntas: $\mathrm{S}=\operatorname{sim}$ ou $\mathrm{N}=\mathrm{Não}$.

Critérios de inclusão:

O Sr.(a),

( ) Reside no distrito federal? Bairro?

( ) Tem idade igual ou superior a 60 anos?

( ) Tem atestado médico de liberação para exercícios resistidos?

Critérios de exclusão:

O Sr. (a)

( ) Possui algum problema de saúde (doença)?

Qual(s):

( ) Tem hipertensão arterial (>150/90 mmHg)?

Medicamento em uso:

Algum outro medicamento?

( ) Sofreu infarto do miocárdio nos últimos 6 meses?

( ) Tem marcapasso no coração?

( ) Já fez alguma cirurgia para colocação de prótese?

Local:

( ) Tem fez alguma cirurgia para colocação de placa e/ou parafuso?

Local:

( ) Fez alguma cirurgia nos últimos 6 meses?

Tipo/região:

( ) Sofreu fratura óssea ou lesão muscular nos últimos 6 meses?

Local:

( ) Faz algum tipo de treinamento resistido nos últimos 06 meses?

Qual(s):

( ) Faz uso de terapia hormonal (mulheres apenas)?

( ) Sofreu fratura óssea ou lesão muscular nos últimos 6 meses?

Local:

( ) Faz algum tipo de treinamento resistido nos últimos 06 meses?

Qual(s):

( ) Faz uso de terapia hormonal (mulheres apenas)? 


\title{
ANEXO A- PARECER DO COMITÊ DE ÉTICA
}

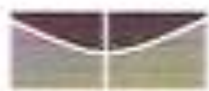 \\ Iniveraidiale cle Brasilit \\ Faculidade de Cièncias da Sride

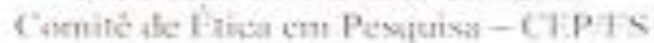

\section{PROCESSO DE ANALISE DE PROJETO DE PESQUISA}

\author{
Repistop do Projeto no CE[: 081/11

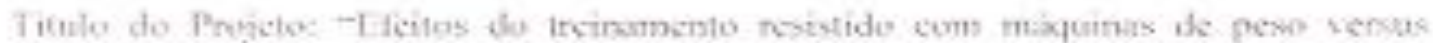

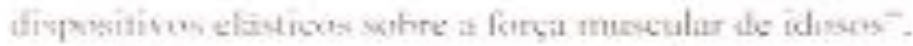 \\ Etcwquisadera 1Resgonsavel: Nagner Rodrigucs Martins.

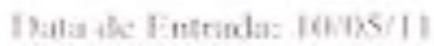

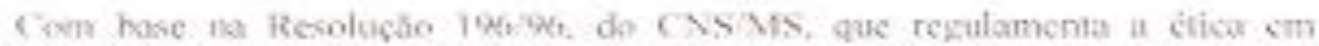

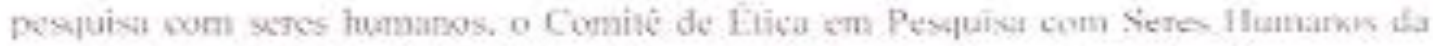

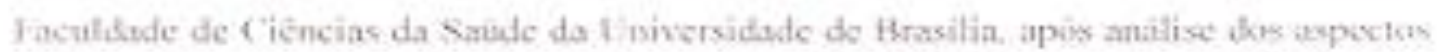

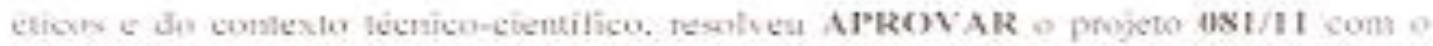

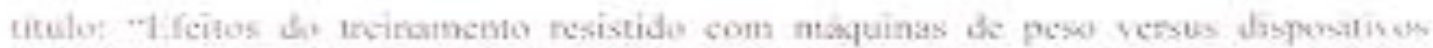

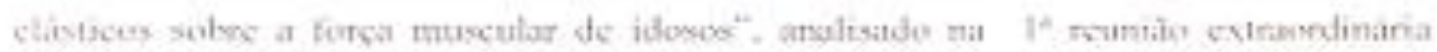
resilicale nos dia $3 \mathrm{R}$, fe jumber de 2011

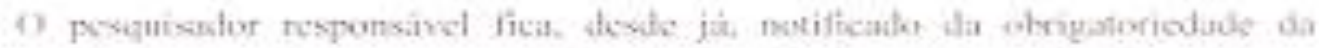

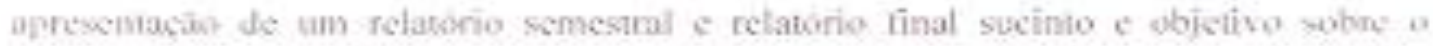

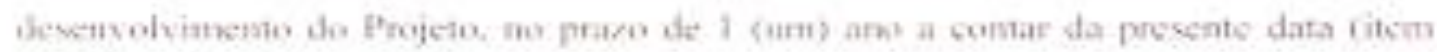
VII, 13 dn Resoluçao $1 \%, 96 \%$.

Wravitia. 21 se jalhode $24 n 1$.

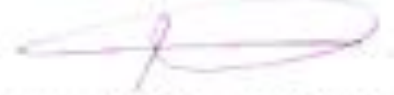

Thiugo Rocka da C imha Vice - covrdemudor do (-1:12-18:1 ints 
ANEXO B - IMAGENS DOS EXERCíCIOS REALIZAdOS NAS MÁQUINAS PNEUMÁTICAS E NA RESISTÊNCIA ELÁSTICA.

Figura 2. Exercício supino realizado no GRE e GMP fase inicial e final
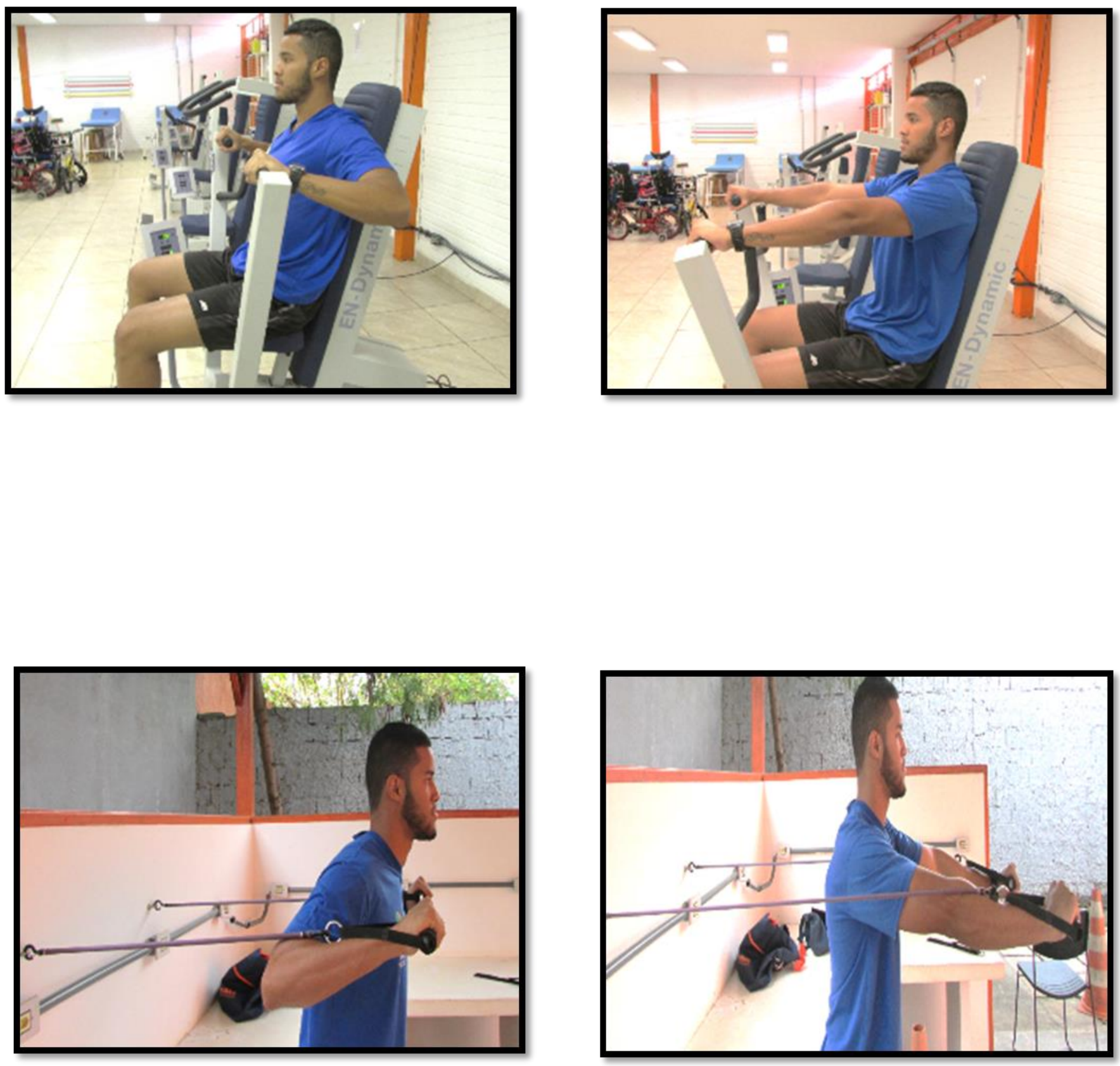
Figura 3. Exercício remada realizado no GRE e GMP fase inicial e final
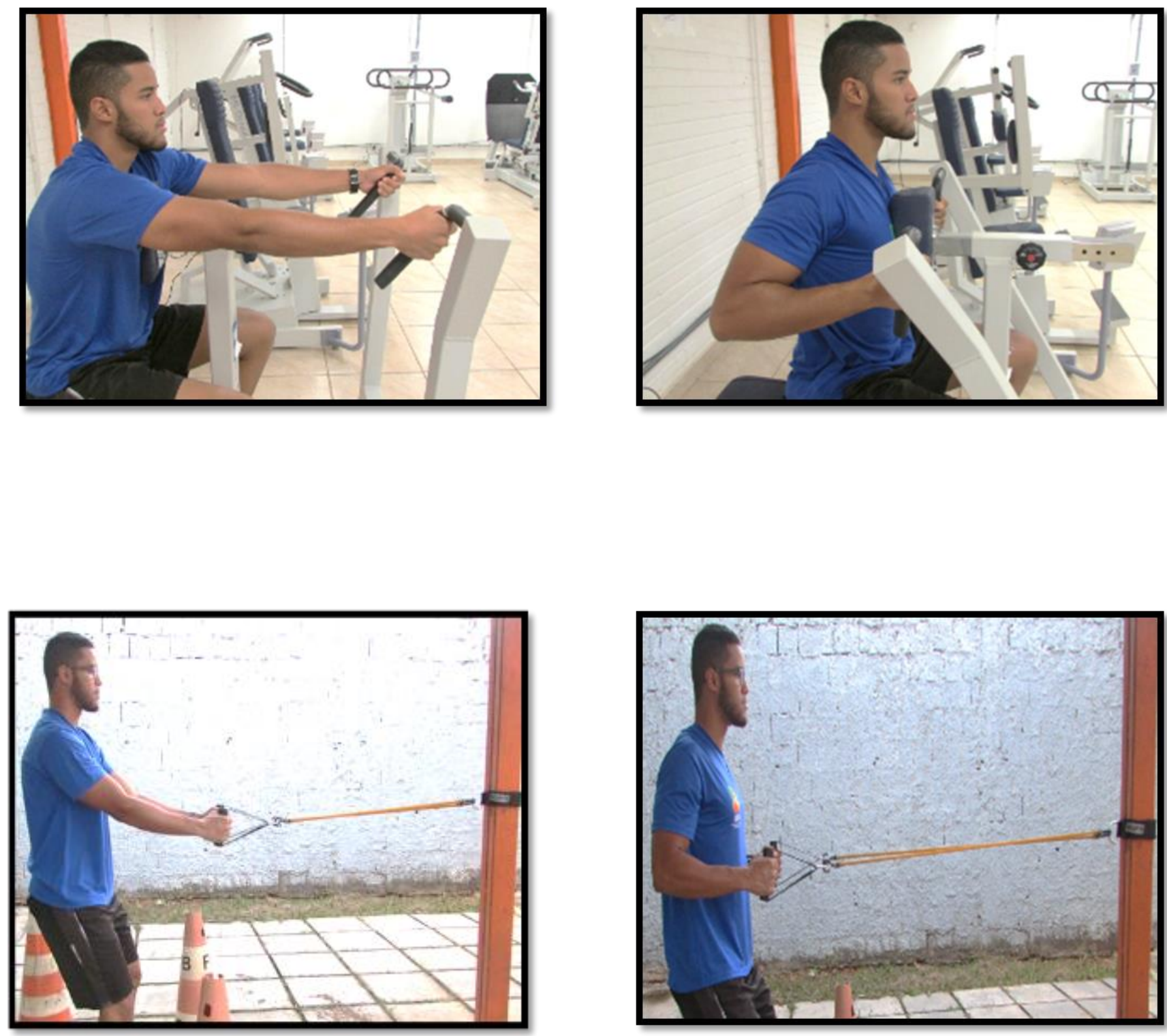
Figura 4. Exercício puxada alta realizado no GRE e GMP fase inicial e final
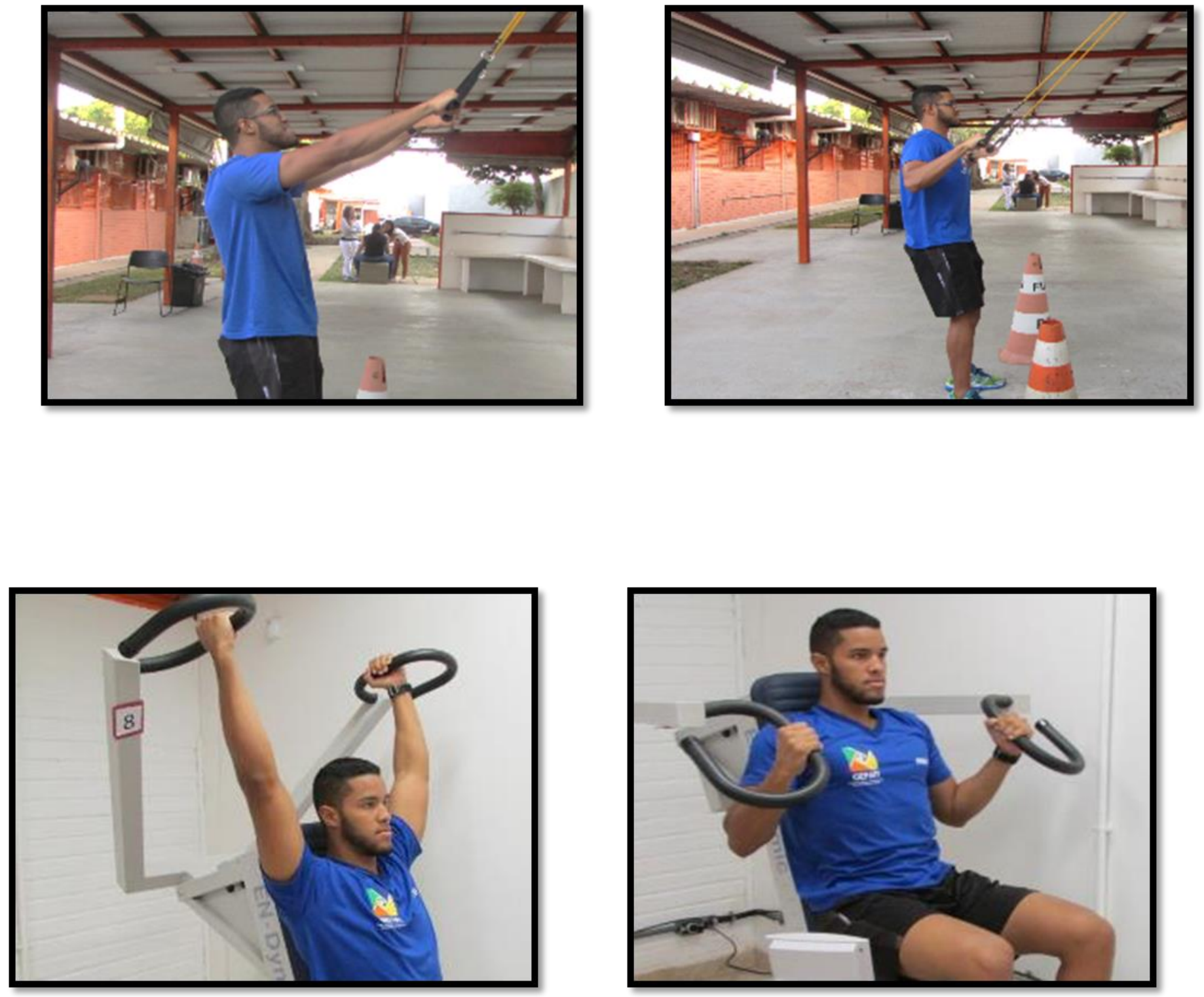
Figura 5. Exercício tríceps realizado no GRE e GMP fase inicial e final
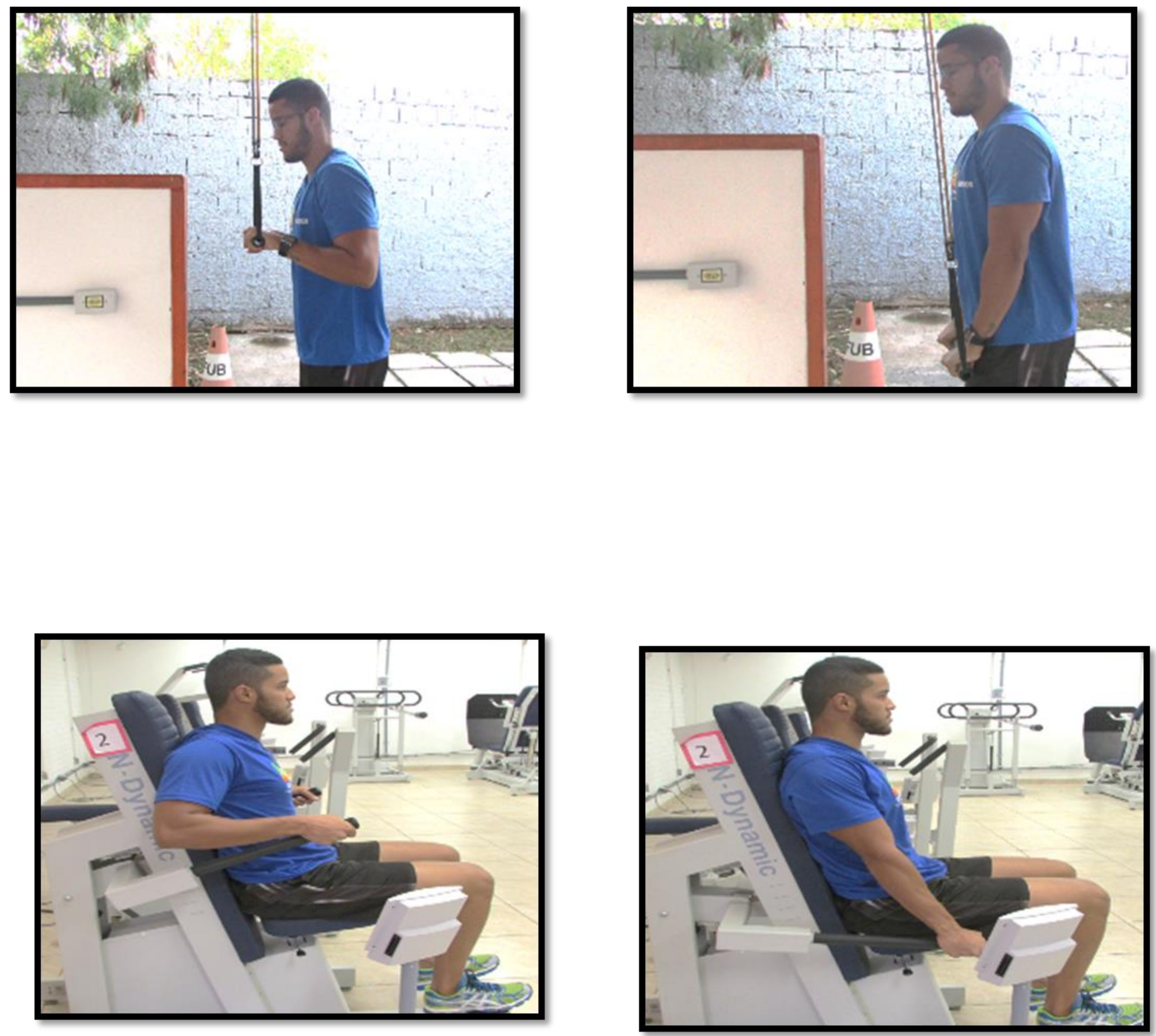
Figura 6. Exercício abdução realizado no GMP e GRE fase inicial e final
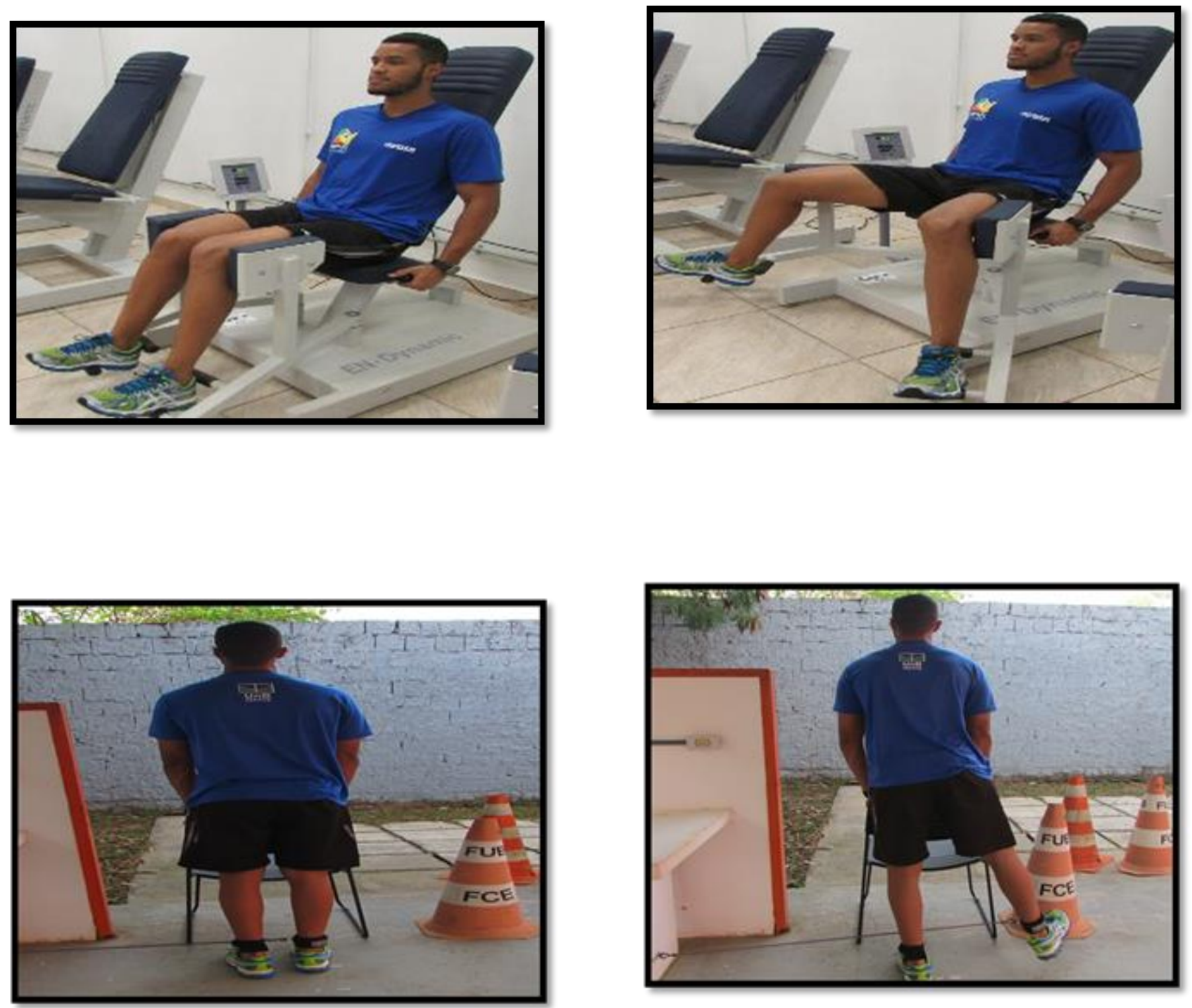
Figura 7. Exercício de extensão de quadril realizada no GMP e GRE fase inicial e final.
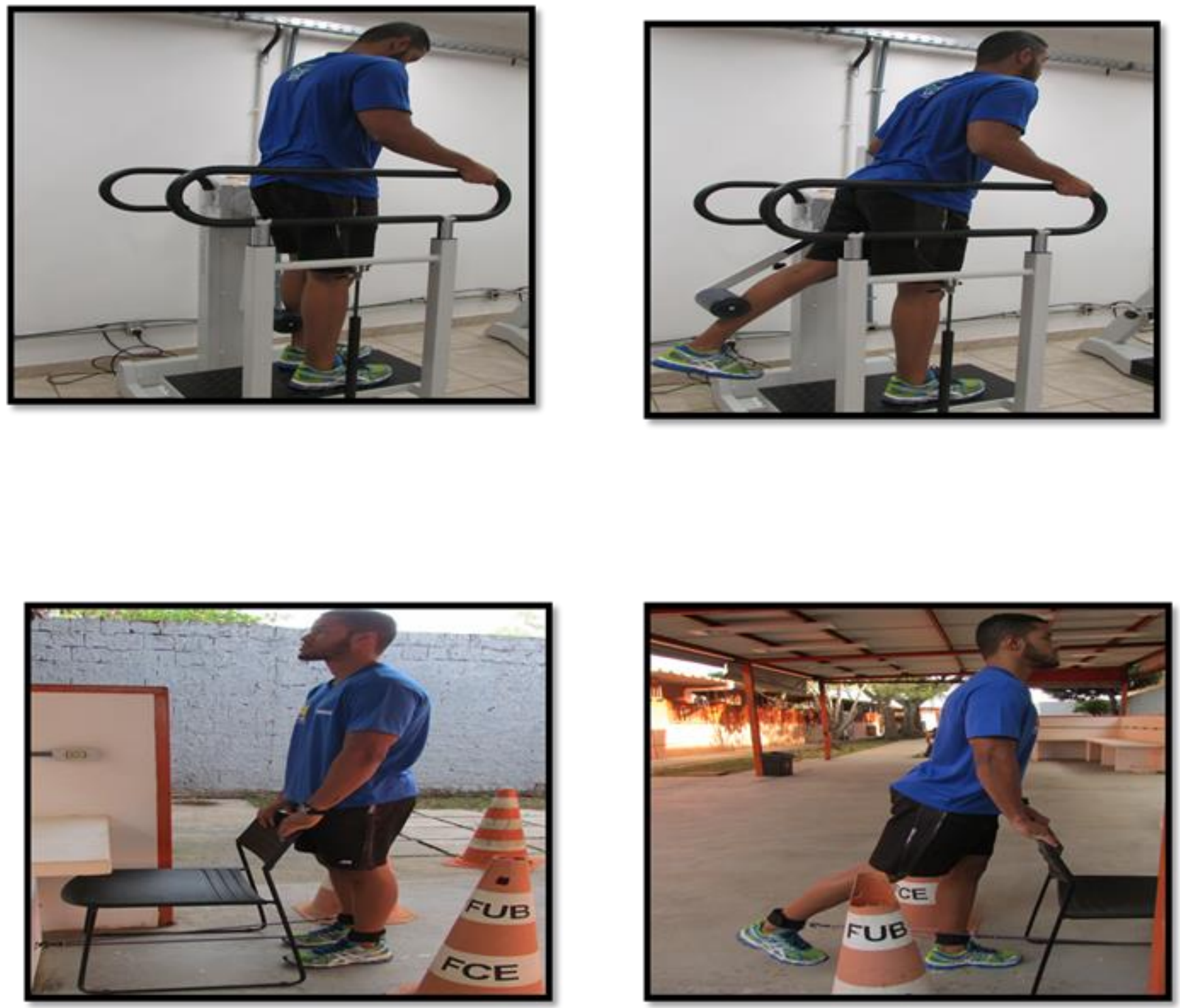
Figura 8. Exercício deslocamento no GRE e Abdução no GMP
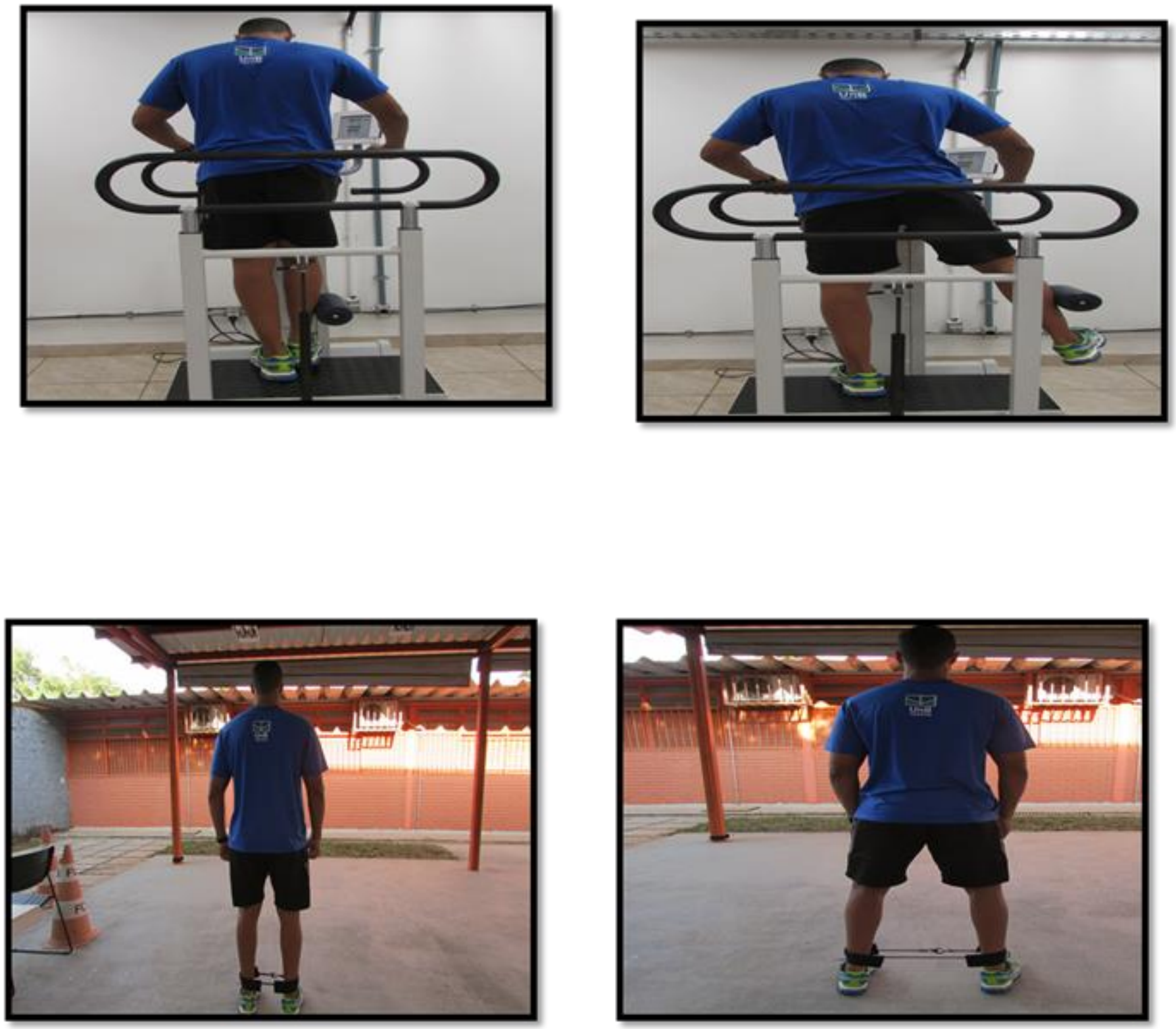
Figura 9. Exercício de flexão joelho realizado no GRE e GMP.
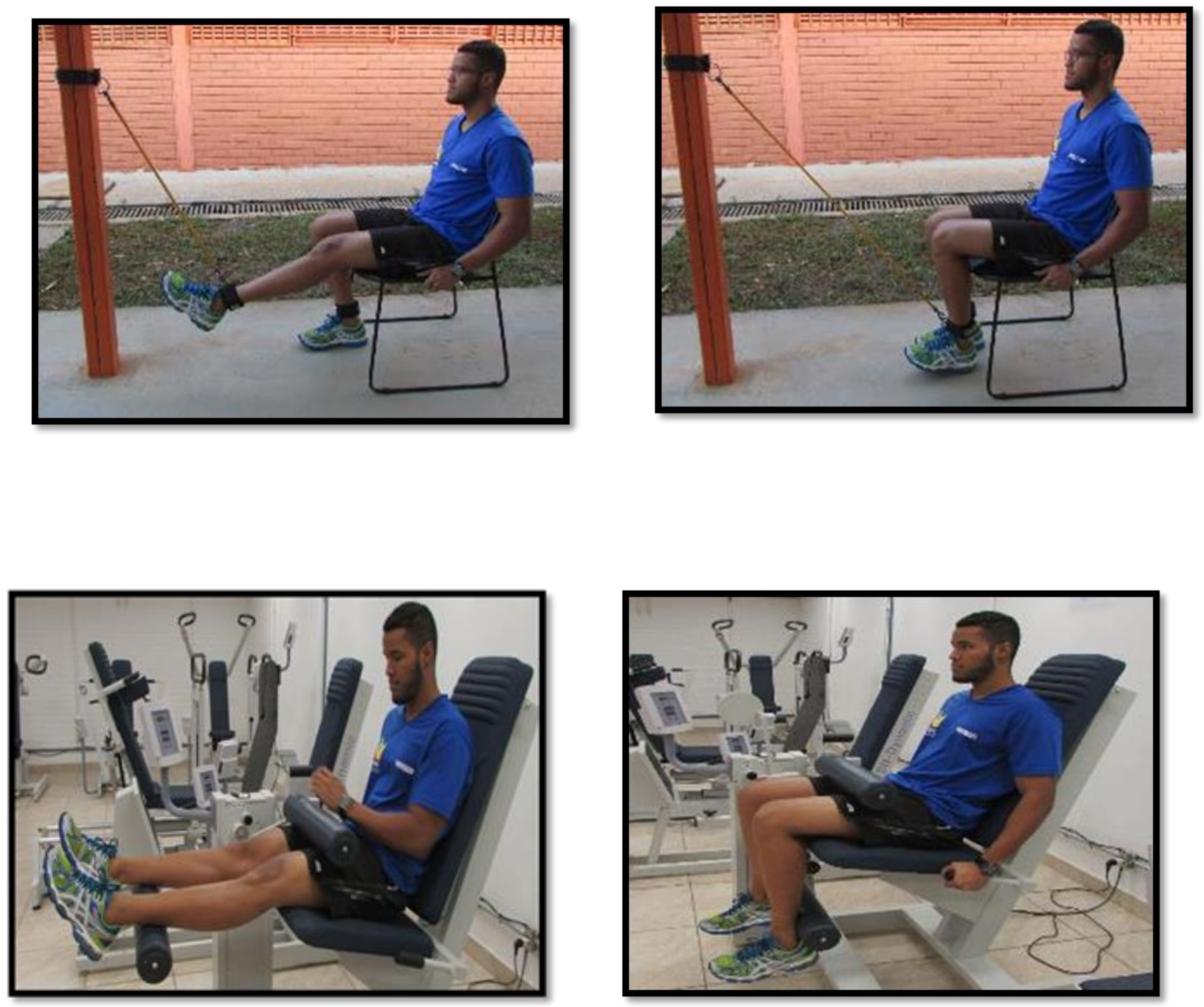
Figura 10. Exercício de extensão de joelho no GRE e GMP
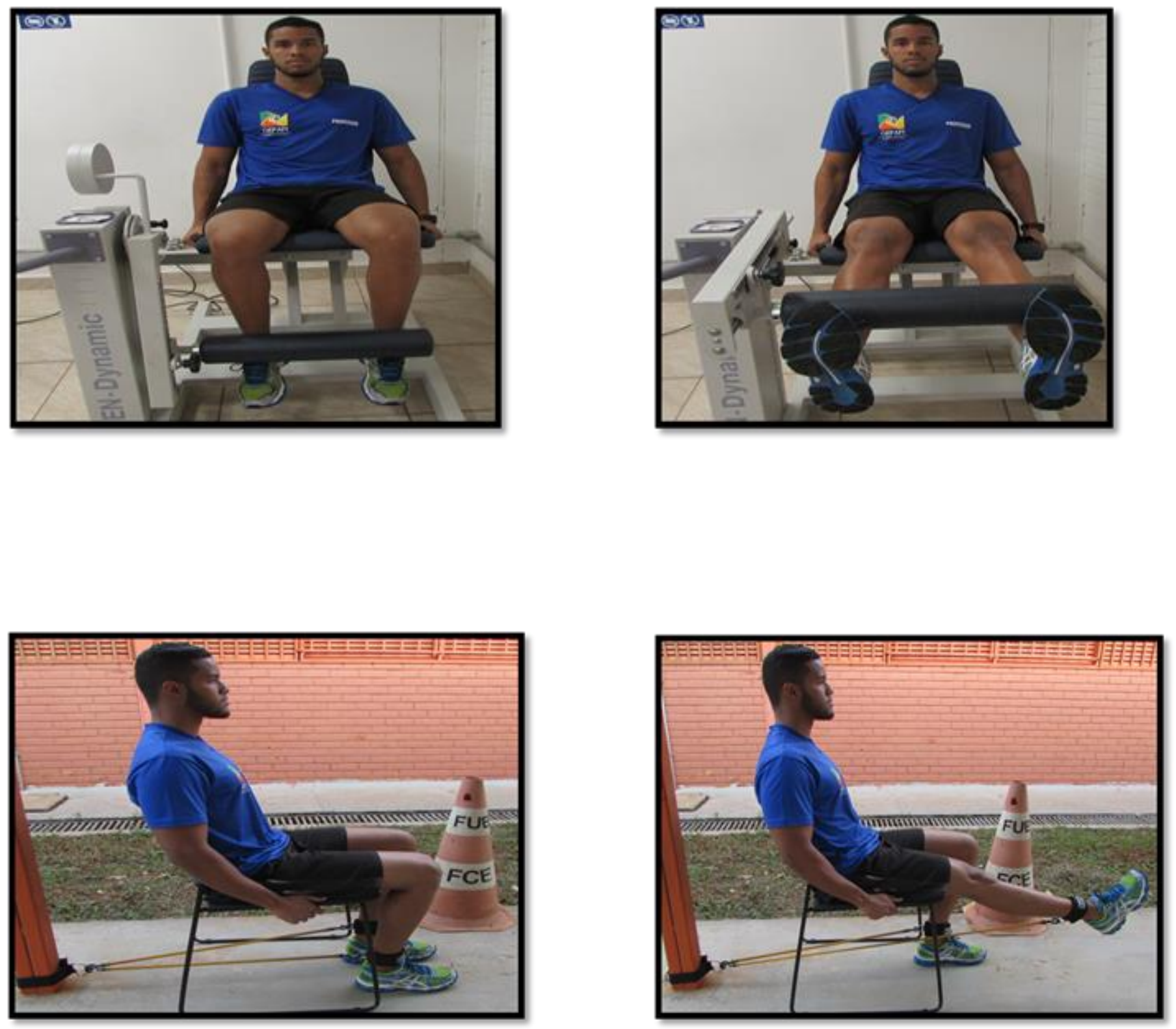